\title{
Use of the Earth's Surface as a Reference to Correct Airborne Nadir-Looking Radar Radial Velocity Measurements for Platform Motion
}

\author{
Scott M. Ellis, Peisang Tsai, Christopher Burghart, Ulrike Romatschke, Michael Dixon, \\ JOTHIRAM VIVEKANANDAN, JONATHAN EMMETT, AND ERIC LOEW
}

Earth Observing Laboratory, National Center for Atmospheric Research, Boulder, Colorado

(Manuscript received 4 February 2019, in final form 5 May 2019)

\begin{abstract}
A technique for correcting radar radial velocity $\mathrm{Vr}$ in airborne, nadir-pointing radar data using the surface of Earth as a reference is proposed and tested. Operating airborne Doppler radars requires correcting the radial velocity for platform motion. This can be accomplished with accurate beam-pointing and platform motion measurements. However, there are often residual pointing errors due to drift in inertial navigation systems (INS) and/or errors in platform-relative pointing. The technique proposed here takes advantage of the fact that the surface is stationary and the mean of the measured $\mathrm{Vr}$ at the surface $\mathrm{Vr}_{\text {surf }}^{\text {meas }}$ should be $0 \mathrm{~m} \mathrm{~s}^{-1}$. Therefore, if a good estimate of the mean $\mathrm{Vr}_{\text {surf }}^{\text {meas }}$ is made, it can be subtracted from the measured $\mathrm{Vr}$ to correct for errors due to residual pointing errors. The $\mathrm{Vr}_{\text {surf }}^{\text {meas }}$ data contain many independent deviations from $0 \mathrm{~m} \mathrm{~s}^{-1}$ due to various causes, including measurement variance and large deviations due to surface features. These deviations must be filtered out of $\mathrm{Vr}_{\text {surf }}^{\mathrm{meas}}$ before the surface reference can be applied to correct the Vr data. A two-step filtering process was developed and tested. The first step removes large deviations in $\mathrm{Vr}_{\text {surf }}^{\text {meas }}$ and the second step removes the measurement noise. The technique was examined using data from three field campaigns and was found to improve the quality of $\mathrm{Vr}$ in all cases. The Vr bias was removed and the variance was substantially reduced. The approach is generally applicable to nadir-pointing airborne radar data.
\end{abstract}

\section{Introduction}

Correcting Doppler velocity measurements from airborne weather radar for errors due to platform motion is important to obtaining usable radial velocity $(\mathrm{Vr})$ measurements and has many challenges. The radarmeasured Vr can be expressed as $\hat{\mathbf{k}} \mathbf{v}_{h}+\hat{\mathbf{k}} \mathbf{v}_{p}$, where $\mathbf{v}_{p}$ is the platform velocity, $\mathbf{v}_{h}$ is the hydrometeor velocity, and $\hat{\mathbf{k}}$ is a unit vector in the direction of the radar beam (Durden et al. 1999). Because $\mathbf{v}_{p}$ and $\hat{\mathbf{k}}$ are independent of range, the component of $\mathrm{Vr}$ due to platform motion is constant for individual beams and a single correction value is needed for each radar beam.

The correction is most often made by measuring the platform motion and the radar beam pointing angle and accounting for them within the radial $\mathrm{Vr}$ measurements (Heymsfield 1989; Lee et al. 1994; Testud et al. 1995; Bosart et al. 2002; Cai et al. 2018). For example, the NASA ER-2 Doppler radar (EDOP; Heymsfield et al. 1996) and Wyoming Cloud Radar (WCR; Haimov and

Corresponding author: Scott Ellis, sellis@ucar.edu
Rodi 2013) use geometric corrections (e.g., Lee et al. 1994) to remove platform motion from Vr utilizing a well-calibrated radar pointing angle. The actual radar beam pointing angle depends on the platform attitude and the platform-relative antenna pointing angle. The platform-relative pointing angle can be well calibrated following Haimov and Rodi (2013), but there may still be small residual errors. Small errors in the measured radar beam pointing angle can result in large $\mathrm{Vr}$ errors especially on a fast-moving platform. For radar observations at vertical incidence, $\mathrm{Vr}$ accuracies of less than $0.1 \mathrm{~m} \mathrm{~s}^{-1}$ are desirable in order to observe small updrafts and downdrafts and to resolve ice crystal fall speeds that are on the order of a few tenths of a meter per second (Rauber et al. 2017). Here, we propose a Vr correction technique that utilizes the stationary echo from Earth's surface as a reference for the correction.

A surface reference was used by Durden et al. (1999) to correct $\mathrm{Vr}$ on the scanning Airborne Rain Mapping Radar (ARMAR) 14-GHz Doppler radar. They used a recursive least squares fit of a model for the surface Doppler observed over several scans through nadir 
(Durden et al. 1999). The main limitation of the method was the time resolution of the correction was fairly coarse and the aircraft was assumed to be steady over that time. Their method was designed for use when aircraft navigation data were not available.

The correction proposed here was developed with, and applied to, nadir-pointing data from the National Center for Atmospheric Research (NCAR) HIAPER Cloud Radar (HCR; Vivekanandan et al. 2015). HCR is a W-band, dual-polarization, Doppler airborne research radar that flies in an underwing pod on the NSF/NCAR Gulfstream-V High-Performance Instrumented Airborne Platform for Environmental Research (GV HIAPER) aircraft (UCAR/NCAR 2005). A lens antenna illuminates a reflector enabling cross-track scanning as well as staring, for example, nadir or zenith. One important characteristic of HCR is its ability to stabilize the beam for changes in platform attitude in real time during flight. Beam stabilization is only available during staring operations and is accomplished by reading in the platform position and motion data from the dedicated Inertial Navigation System with coupled Global Position System (INS/ GPS) located near the radar's reflector. The pointing angle is updated at $20 \mathrm{~Hz}$, thus keeping the beam pointed very close to the desired direction. At vertical incident, this strategy mitigates the errors from the unknown horizontal wind that are projected into a nonvertical pointing beam, which can be substantial for relatively small offsets (Vivekanandan et al. 2015).

Modern INSs are coupled with GPS that helps correct the INS data. This coupling helps to reduce errors due to drift in the INS accuracy during straight and level flight, first described by Schuler (1923), by applying a Kalman filter error correction method. However there is still noticeable drift in the platform orientation measurements that occur in the absence of accelerations such as turns. This is mainly because the INS heading measurement is poorly constrained in straight and level flight and drifts over time. These heading errors can be projected into the tilt and rotation angle directions if there are any errors in their initial values. For example, the INS/GPS unit used with the HCR has a stated heading drift of $0^{\circ}-10^{\circ} \mathrm{h}^{-1}$ and a tilt error of $\pm 0.06^{\circ}$. At ground speeds typical for HCR of 150,200 , and $250 \mathrm{~m} \mathrm{~s}^{-1}$, this small tilt error results in $\mathrm{Vr}$ errors of $0.16,0.21$, and $0.26 \mathrm{~m} \mathrm{~s}^{-1}$, respectively, which are large errors relative to, for example, ice crystal fall speeds. This in part motivates the development of a surface-based correction method.

Another source of error that the surface-based correction addresses is errors in platform vertical motion and beam pointing that are transient in time and vary as the aircraft altitude and pitch angle change during flight.
This causes variable errors in $\mathrm{Vr}$ that are difficult to address without an external reference. The manufacturer specification for the vertical velocity of the INS/GPS unit is given as a standard deviation of $0.1 \mathrm{~m} \mathrm{~s}^{-1}$.

The idea of the surface-reference correction is to filter out the measurement noise and other variations from $0 \mathrm{~m} \mathrm{~s}^{-1}$ in the surface $\mathrm{Vr}$ signal and then subtract the remaining mean $\mathrm{Vr}$ at the surface from the entire beam. This approach normalizes the $\mathrm{Vr}$ at the surface to $0 \mathrm{~m} \mathrm{~s}^{-1}$ and correcting $\mathrm{Vr}$ throughout the domain for errors due to pointing errors. The correction has been developed using nadir staring data and only corrects for $\mathrm{Vr}$ errors arising from errors in pointing angle and platform motion measurements. $\mathrm{Vr}$ errors due to horizontal winds are not accounted for by the proposed method. The wind errors are mitigated by the beam stabilization.

A serious challenge for using the surface echo to correct $\mathrm{Vr}$ measurements over land is the common occurrence of nonzero mean $\mathrm{Vr}$ echoes due to highly reflective features on the surface such as roads, creeks, or buildings. Large excursions from $0 \mathrm{~m} \mathrm{~s}^{-1}$ mean $\mathrm{Vr}$ occur due to the finite beamwidth of the radar and the platform motion. To remove these large excursions requires application of a filter of sufficiently large filter response. However, that filter response would cause errors in the $\mathrm{Vr}$ correction in other regions. This issue led to the development of the proposed two-stage filtering process, which removes the large excursions without causing errors elsewhere. This two-stage approach is similar in concept to the iterative filter technique developed by Hubbert and Bringi (1995) used to remove the phase shift upon backscatter from the measured differential phase in polarimetric radar data. To our knowledge this is the first time that a twostage filter method has been used to correct airborne Doppler radar data.

In section 2 the data presented in this study are briefly described, followed by a description of the challenges for using the surface for Vr correction and the proposed method in section 3. Results are shown in section 4 with a summary and conclusions provided in section 5 .

\section{Data}

The data presented in this study come from three different field programs: (i) Nor'easter (Rauber et al. 2017), (ii) the Cloud System Evolution in the Trades (CSET; Albrecht et al. 2018), and (iii) the Southern Ocean Clouds, Radiation, Aerosol Transport Experimental Study (SOCRATES). The Vr data presented have the convention of positive (negative) values moving 
away from (toward) the radar. So at nadir, positive values of $\mathrm{Vr}$ represent downward motion.

The Nor'easter flight was a single-mission, rapidresponse field study utilizing the HCR. The HCR was operated in nadir-staring mode with beam stabilization enabled during both the ferry flight to Raleigh and the research flight (Rauber et al. 2017).

The observing strategy for the CSET field program was to sample clouds and marine boundary layer features on a flight from Sacramento, California, to Kona, Hawaii. The HCR was operated at both nadir and zenith pointing depending on whether or not HIAPER was above or below the clouds being studied. The beam stabilization was employed for the entire experiment.

The SOCRATES field program was based out of Hobart, Australia, and flew its missions over the Southern Ocean. The primary strategy was to ferry over the target area at $6.0 \mathrm{~km}$ while sampling the area with HCR and the high-spectral-resolution lidar (HSRL; Eloranta 2005) to identify potential aircraft icing regions. Low-level flight modules similar to CSET were flown on the way back to Hobart with both nadir- and zenith-pointing HCR operations and beam stabilization.

\section{Surface-reference Vr correction challenges and method}

The technique described here for correcting measured $\mathrm{Vr}$ at all range bins relies on the fact that the surface is stationary. This means that after correction for the platform motion while taking into account the radar pointing angle, the true $\mathrm{Vr}$ of the surface echo is $0 \mathrm{~m} \mathrm{~s}^{-1}$. Any residual error in the measured $\mathrm{Vr}$ due to pointing errors after the platform motion correction has been applied $\mathrm{Vr}^{\text {meas }}$ will appear as an offset from $0 \mathrm{~m} \mathrm{~s}^{-1}$ in $\mathrm{Vr}^{\text {meas }}$ at the range gate corresponding to the surface echo $\mathrm{Vr}_{\text {surf }}^{\text {meas }}$. The term $\mathrm{Vr}^{\text {meas }}$ in this paper refers to the measured $\mathrm{Vr}$ after all pointing-angle and platform motion corrections have been applied, but before the surface-reference correction is used. In the absence of other errors $\mathrm{Vr}_{\text {surf }}^{\text {meas }}$ should be $0 \mathrm{~ms}^{-1}$. However, there are several other sources of random errors in $\mathrm{Vr}_{\text {surf }}^{\text {meas }}$ that are independent of the rest of the radar data, which will be described in this section. Therefore if all of the independent errors besides those due to pointing angle and platform motion are removed from $\mathrm{Vr}_{\text {surf }}^{\text {meas }}$, then it could be subtracted from $\mathrm{Vr}^{\text {meas }}$ in all range gates within the entire ray to correct for systematic errors due to beam-pointing and platform motion errors. These independent errors in $\mathrm{Vr}_{\text {surf }}^{\text {meas }}$ must be removed before making the subtraction of the surface $\mathrm{Vr}$; otherwise, large errors in the corrected Vr will result.
The approach taken here is to filter $\mathrm{Vr}_{\text {surf }}^{\text {meas }}$ to remove the independent, random errors and then subtract this filtered surface $\mathrm{Vr}\left(\mathrm{Vr}_{\text {surf }}^{\text {filt }}\right)$ from $\mathrm{Vr}^{\text {meas }}$ in each range bin. At the same time the filter must not remove any variations from systematic errors that impact all $\mathrm{Vr}$ measurements at all ranges, such as changes in beampointing-angle error or vertical velocity error over time. So a filter that removes independent errors of $\mathrm{Vr}_{\text {surf }}^{\text {meas }}$, but fits the systematic errors will allow the use of the surface as an absolute reference correction without introducing different sources of error in $\mathrm{Vr}_{\text {surf }}^{\text {meas }}$ into the rest of the radar domain.

To use the surface reference for radial velocity correction, three steps are required: (i) identify the surface echo, (ii) filter the measured $\mathrm{Vr}_{\text {surf }}^{\text {meas }}$ to obtain $\mathrm{Vr}_{\text {surf }}^{\text {filt }}$, and (iii) subtract $\mathrm{Vr}_{\text {surf }}^{\text {filt }}$ from $\mathrm{Vr}^{\text {meas }}$ along each radar beam.

\section{a. Identifying the surface echo}

Misidentifying the surface echo will result in large $\mathrm{Vr}$ errors introduced by the correction method. Thus it is important to have a highly reliable surface identification method in place. The surface reflectivity values are usually higher than those of intervening precipitation and cloud echoes. However, attenuation of the beam between the aircraft and the surface may reduce the measured $\mathrm{Ze}_{\text {surf }}^{\text {meas }}$, or even obscure it entirely.

To identify the surface echo in each radial, the range gate with maximum reflectivity Ze within $1 \mathrm{~km}$ of the surface location is used, which requires a digital terrain map. In this study the U.S. Geological Society (USGS) global digital elevation model (DEM) with a horizontal resolution of 30 arc s (approximately $1 \mathrm{~km}$ ) was used (Earth Resources Observation and Science Center 1997). If a terrain map is not available the $1-\mathrm{km}$ restriction may need to be relaxed or removed. In practice three range bins are examined, the bin with maximum $\mathrm{Ze}$ and the range bins on either side. If any of those three range bins have Ze less than $8 \mathrm{dBZ}$, then the surface-based Vr correction is not made.

Using three range bins in this way prevents small point targets, such as birds, from being mistakenly identified as the surface. The HCR was run with a $40-\mathrm{m}$ pulse length that was oversampled by a factor of 2 to $20-\mathrm{m}$ range gates [complete system characteristics can be found in Vivekanandan et al. (2015)]. The result is that the surface echo typically occupies several range bins.

The 8-dBZ threshold is used to avoid misidentifying the surface echo in the case of strong attenuation from clouds and precipitation above the surface. The surface is typically very strong compared to clouds and precipitation and was as high as $45 \mathrm{dBZ}$. It was found that the surface could be reliably identified in the presence of strong attenuation, but if the signal became too weak, 


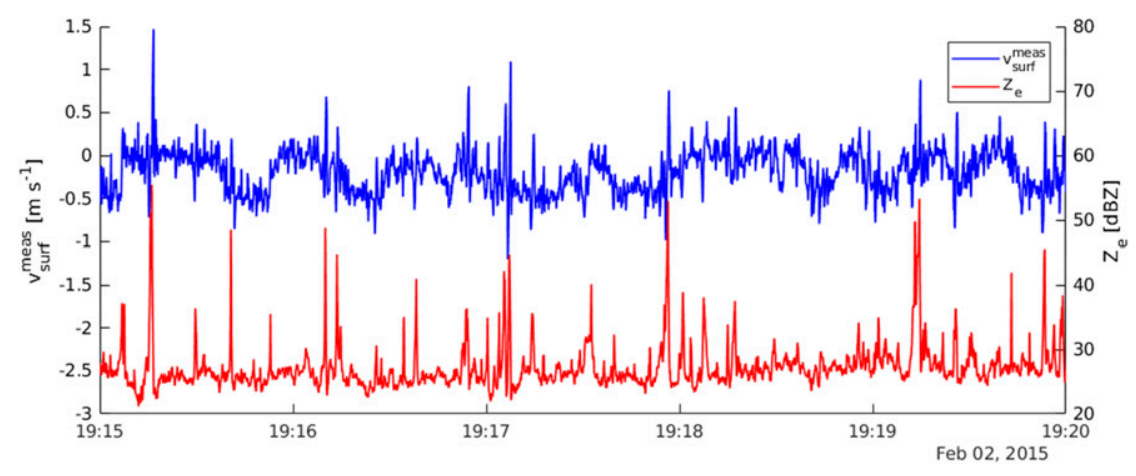

FIG. 1. Times series of $\mathrm{Vr}_{\text {surf }}^{\text {meas }}$ (blue) and $\mathrm{Ze}_{\text {surf }}^{\text {meas }}$ (red) for the Nor'easter flight from 1915 to 1920 UTC 2 Feb 2015.

misidentifications could occur. The threshold value of $8 \mathrm{dBZ}$ was found empirically and works well for HCR.

It is important to point out that the general approach of surface identification should work on other radar systems, but the number of range bins used and the $\mathrm{Ze}$ threshold may need to be changed for different radars particularly at different wavelengths.

\section{$b$. Filtering the surface $\mathrm{Vr}$}

Figure 1 shows an example of the $\mathrm{Vr}_{\text {surf }}^{\text {meas }}$ (blue line) over a 5-min period taken during the Nor'easter field program over land. Each data point in the plot represents the identified ground echo for one radar beam. The data have been corrected for the measured pointing angle and platform motion following Lee et al. (1994) using the measured orientation and motion of the wingpod from INS/GPS and the wingpod-relative pointing angles measured by the radar. The mean of $\mathrm{Vr}_{\text {surf }}^{\text {meas }}$ shown is $-0.17 \mathrm{~m} \mathrm{~s}^{-1}$, which translates to an average along-track pointing error of about $0.05^{\circ}$ given that the mean ground speed of the aircraft is $194.0 \mathrm{~m} \mathrm{~s}^{-1}$. It can be seen in Fig. 1 that there are $\mathrm{Vr}_{\text {surf }}^{\text {meas }}$ deviations from the mean at various frequencies and amplitudes and the filter technique must appropriately address each of them in order for the surface-reference correction to work properly. This subsection briefly describes the different observed $\mathrm{Vr}_{\text {surf }}^{\text {meas }}$ deviations from the mean and then describes the filtering approach developed.

\section{1) MEASUREMENT UNCERTAINTY}

The random measurement errors in $\mathrm{Vr}_{\text {surf }}^{\text {meas }}$ can be seen in Fig. 1 as the high-frequency oscillations with an amplitude of about $0.1-0.2 \mathrm{~m} \mathrm{~s}^{-1}$. The measurement errors resulting from the radar system depend on the number of independent samples in each radar volume, which is a function of the pulse repetition frequency, integration time and the spectrum width (e.g., Vivekanandan et al. 2015, their Fig. 5; Doviak and Zrnić 1993). Other sources of measurement error in $\mathrm{Vr}_{\text {surf }}^{\text {meas }}$ include nonuniform beam filling at the surface and random motions on the surface.

Since the measurement uncertainty errors at the surface are independent of the errors at other ranges, the filter process must remove them before $\mathrm{Vr}_{\text {surf }}^{\mathrm{filt}}$ can be subtracted from $\mathrm{Vr}^{\text {meas }}$ to correct the data.

\section{2) VARIABLE VR ERROR}

There are also deviations from the mean noticeable in $\mathrm{Vr}_{\text {surf }}^{\text {meas }}$ (Fig. 1, blue line) with a period of about $15-45 \mathrm{~s}$ and an amplitude around $0.5 \mathrm{~m} \mathrm{~s}^{-1}$. There are two likely sources of these slower oscillations around the mean.

The first is variable beam-pointing errors. The pointing error changes as the reflector tilt angle (relative to the wingpod) is moved in-flight to compensate for changes of the plane's pitch angle in order to achieve a stabilized beam. The period of the variable pointing errors is related to the motion of the aircraft. Flat and level flight using the autopilot often results in smallamplitude oscillations in pitch angle and altitude as the control system works to keep the aircraft at a constant pressure altitude. It is these oscillations to which the beam stabilization is reacting. By examining the data and the reflector gears after Nor'easter, it was determined that there was gear backlash, or play in the gears that control the reflector pointing angle. The gear backlash had increased over time due to wear on the gears. New gears with a tighter tolerance and made of a harder, more wear-resistant material were installed after Nor'easter and the magnitude of the variable $\mathrm{Vr}$ errors was greatly reduced. This indicated that the variable $\mathrm{Vr}$ errors observed during Nor'easter were dominated by the gear backlash impacting the pointing accuracy as the reflector pointing angle was moved during stabilization.

The second potential source of the variable Vr errors is uncertainty in the INS/GPS measured vertical velocity of the platform. Measurements of the vertical velocity 
from the INS/GPS can have errors that are significant relative to the desired $\mathrm{Vr}$ accuracy of vertically pointing radar data. The INS/GPS unit used by HCR has a variance of $0.1 \mathrm{~m}^{2} \mathrm{~s}^{-2}$.

These variable $\mathrm{Vr}$ errors were not consistent enough to be related in a deterministic fashion to the radar orientation and vertical velocity so could not be corrected using the platform motion correction of Lee et al. (1994). Since variable velocity errors impact all of the $\mathrm{Vr}^{\text {meas }}$ data along each beam, $\mathrm{Vr}_{\text {surf }}^{\text {filt }}$ must fit these lower-frequency deviations so that these errors will be removed at all ranges when $\mathrm{Vr}_{\text {surf }}^{\text {filt }}$ is subtracted from $\mathrm{Vr}^{\text {meas }}$.

\section{3) Surface Vr anomalies}

Figure 1 shows numerous large deviations from the mean $\mathrm{Vr}_{\text {surf }}^{\text {meas }}$ that appear as spikes in both the positive and negative directions with amplitudes exceeding $1 \mathrm{~m} \mathrm{~s}^{-1}$ in some cases. The positive and negative spikes are most often paired together. Comparing the blue and red lines in Fig. 1, it can be seen that the spikes in $\mathrm{Vr}_{\text {surf }}^{\text {meas }}$ are coincident with positive spikes in surface $\mathrm{Ze}\left(\mathrm{Ze}_{\text {surf }}^{\text {meas }}\right)$ with deviations from the mean from about 5 to $25 \mathrm{~dB}$. It is tempting to view these as outliers, but these spikes contain up to about a dozen data points. The spikes in $\mathrm{Vr}_{\text {surf }}^{\text {meas }}$ are due to the platform motion combined with the finite beamwidth radar beam passing highly reflective targets smaller than the surface radar footprint. This sets up strong Ze gradients across the radar beam resulting in negative (approaching) followed by positive (receding) $\mathrm{Vr}$ anomalies as the radar flies over them. Targets that result in these anomalies include a large number of different features such as roads, creeks, buildings, and ships. The generation of these $\mathrm{Vr}_{\text {surf }}^{\text {meas }}$ and $\mathrm{Ze}_{\text {surf }}^{\text {meas }}$ spikes is discussed in more detail in the appendix.

The surface $\mathrm{Vr}$ anomaly spikes only impact the surface echoes, so the filter process must completely remove them in order to avoid large errors when subtracting $\mathrm{Vr}_{\text {surf }}^{\text {filt }}$ from $\mathrm{Vr}^{\text {meas }}$ for the correction.

It should be noted that all nonuniform surface echoes will always have this effect, but in varying degrees. These varying degrees can be seen in Fig. 1 as large, medium, and small anomalies. The impact of nonuniform surface $\mathrm{Ze}$ will contribute to the variance of the surface Vr.

\section{4) Two-STAGE FILTERING APPROACH}

In the design of the filters we experimented with four different types of filter: (i) moving mean and (ii) moving median, (iii) finite impulse response (FIR) filters, and (iv) regression filters. Because the FIR and regression filters offer much more precise control of the filter response, they were far superior to either mean or median filters for our purpose. It should be noted that other filters may have similar advantages to FIR and regression filters and could also be used. The filters described here were designed using the Nor'easter dataset and applied to both Nor'easter and CSET data. The SOCRATES dataset required a different filter, which is described in the next subsection.

The biggest challenge to using the surface as a reference for correction of $\mathrm{Vr}$ is to design a filter that removes large $\mathrm{Vr}_{\text {surf }}^{\text {meas }}$ anomalies [section $3 b(3)$ ], but still fits the errors with longer periods due to the variable $\mathrm{Vr}$ errors [section $3 \mathrm{~b}(2)$ ]. We were unable to design a single FIR filter that removes the surface anomaly spikes in $\mathrm{Vr}_{\text {surf }}^{\text {meas }}$ while also fitting the oscillations due to the variable $\mathrm{Vr}$ errors. This means that no single FIR filter we found was suitable for the problem, which led to the investigation of a two-stage filter solution.

The stage 1 FIR filter was designed with a response that removes the surface anomaly spikes in $\mathrm{Vr}_{\text {surf }}^{\text {meas }}$. Although the stage 1 filter successfully removes the spikes, its response was such that it would not fit very well the oscillations from the variable $\mathrm{Vr}$ errors. Therefore, the $\mathrm{Vr}_{\text {surf }}^{\text {meas }}$ data filtered with the stage 1 filter $\left(\mathrm{Vr}_{\text {surf }}^{\mathrm{filt1}}\right)$ were only used to remove the surface anomaly spikes. To accomplish this, a new intermediate surface $\mathrm{Vr}$ $\left(\mathrm{Vr}_{\text {surf }}^{\text {intermediate }}\right)$ field was constructed by replacing values of $\mathrm{Vr}_{\text {surf }}^{\text {meas }}$ with the Stage 1 FIR filtered $\mathrm{Vr}_{\text {surf }}^{\text {filt1 }}$ if the magnitude of the difference between $\mathrm{Vr}_{\text {surf }}^{\text {meas }}$ and $\mathrm{Vr}_{\text {surf }}^{\text {filt1 }}$ exceeded a predetermined threshold as

$$
\mathrm{Vr}_{\text {surf }}^{\text {intermediate }}=\left\{\begin{array}{ll}
\mathrm{Vr}_{\text {surf }}^{\text {filt1 }}, & \left|\mathrm{Vr}_{\text {surf }}^{\text {meas }}-\mathrm{Vr}_{\text {surf }}^{\text {filt1 }}\right|>\text { filt1_thresh } \\
\mathrm{Vr}_{\text {surf }}^{\text {meas }}, & \left|\mathrm{Vr}_{\text {surf }}^{\text {meas }}-\mathrm{Vr}_{\text {surf }}^{\text {filt1 }}\right| \leq \text { filt1_thresh }
\end{array} .\right.
$$

In this study the value of filt1_thresh was $0.2 \mathrm{~m} \mathrm{~s}^{-1}$, which is approximately twice the standard deviation of the random measurement errors and was chosen to limit the stage 1 filter to remove only the larger surface anomalies. Experimenting with different values, we found that thresholds between about 0.15 and $0.3 \mathrm{~m} \mathrm{~s}^{-1}$ work well for HCR Nor'easter and CSET data. A different threshold may be required for different radar systems or different HCR operating parameters (different PRF, dwell time, etc.).

The result of the stage 1 filter process is that $\mathrm{Vr}_{\text {surf }}^{\text {intermediate }}$ retains the random measurement errors and the longer-period $\mathrm{Vr}$, but has removed the surface anomaly spikes. This can be seen in Fig. 2, which shows the original $\mathrm{Vr}_{\text {surf }}^{\text {meas }}$ in blue and the $\mathrm{Vr}_{\text {surf }}^{\text {intermediate }}$ results from stage 1 filtering in red.

With the surface anomaly spikes removed it was relatively straightforward to design the stage 2 FIR filter to 


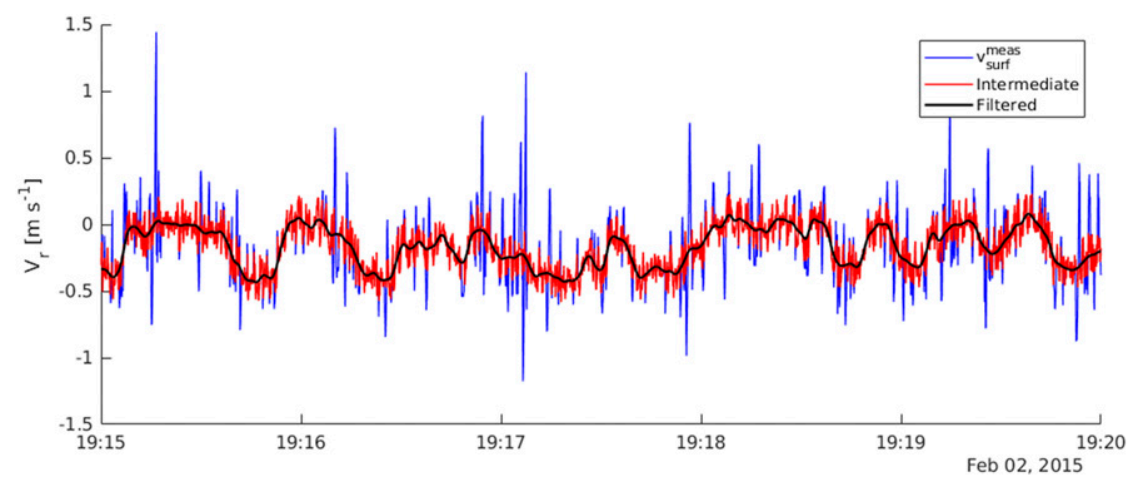

FIG. 2. Time series of $\mathrm{Vr}_{\text {surf }}^{\text {meas }}$ (blue) shown in Fig. 1 along with the intermediate filter field $\mathrm{Vr}_{\text {surf }}^{\text {intermediate }}$ (red) and the final filtered field $\mathrm{Vr}_{\text {surf }}^{\text {filt }}$ (black) that will be used as the correction.

remove the high-frequency measurement error from $\mathrm{Vr}_{\text {surf }}^{\text {intermediate }}$ without removing or smoothing out the lower-frequency $\mathrm{Vr}$ errors that come from the changing beam-pointing and/or vertical velocity errors. The result of the stage 2 filtering applied to $\mathrm{Vr}_{\text {surf }}^{\text {intermediate }}$ to obtain $\mathrm{Vr}_{\text {surf }}^{\text {filt }}$ is shown as the black line in Fig. 2. It can be seen that $\mathrm{Vr}_{\text {surf }}^{\text {filt }}$ has removed almost all of the influence of the surface anomaly spikes and the measurement errors, but fits the errors in $\mathrm{Vr}_{\text {surf }}^{\text {meas }}$ due to pointing errors with longer oscillations well.

\section{5) NONSTATIONARY SURFACE ECHO}

During the SOCRATES field program the HCR sometimes flew over the Southern Ocean at low altitudes. This resulted in a small radar footprint on a surface containing long-wavelength ocean waves, violating at times the assumption of a $0 \mathrm{~m} \mathrm{~s}^{-1} \mathrm{Vr}$ over the surface footprint. The radar evidence that the large swells in the open Southern Ocean caused violation of the stationary surface assumption come from $\mathrm{Vr}_{\text {surf }}^{\text {meas }}$ data that show positive and negative undulations that are not present in the weather echo above as opposed to the variable $\mathrm{Vr}$ errors that show up at all ranges. The SOCRATES data showed that these undulations occasionally had time periods similar to the variable $\mathrm{Vr}$ error. This poses a big challenge for the surface-reference $\mathrm{Vr}$ correction because $\mathrm{Vr}_{\text {surf }}^{\text {filt }}$ must fit to the variable $\mathrm{Vr}$ errors in order to remove them, but at the same time must remove the undulations due to the large waves to avoid introducing errors into the data at all ranges.

The filters used in Nor'easter and CSET described above were found to overfit the $\mathrm{Vr}_{\text {surf }}^{\text {meas }}$ undulations due to ocean waves, causing errors in the corrected $\mathrm{Vr}$. Therefore, a new filter was designed in order to remove more of the waves from $\mathrm{Vr}_{\text {surf }}^{\text {meas }}$. This new filter was a third-degree polynomial regression filter applied over $20 \mathrm{~s}$ of data. Several different regression filters were tested and the new filter yielded reasonable results.
Because the SOCRATES flights were all over water with little ship traffic no two-stage filter process was required to remove surface $\mathrm{Vr}$ anomalies caused by localized high-reflectivity surface echoes.

There were no independent measurements of the ocean waves during SOCRATES and it is not possible to objectively determine the wavelength or height of the waves from the SOCRATES data, however observers from the aircraft noted large swells.

\section{c. Making the surface-reference Vr correction}

The final output of the filtering process $\mathrm{Vr}_{\text {surf }}^{\text {filt }}$ is an estimate of the mean $\mathrm{Vr}_{\text {surf }}^{\text {meas }}$, which should be equal to $0 \mathrm{~m} \mathrm{~s}^{-1}$ in the absence of pointing errors. Therefore, the corrected $\mathrm{Vr}\left(\mathrm{Vr}^{\mathrm{corr}}\right)$ is computed by simply subtracting $\mathrm{Vr}_{\text {surf }}^{\text {filt }}$ from the measured $\mathrm{Vr}$ for each radar beam as

$$
\mathrm{Vr}^{\text {corr }}=\mathrm{Vr}^{\text {meas }}-\mathrm{Vr}_{\text {surf }}^{\text {filt }} \text {. }
$$

\section{Results}

The surface-reference correction for $\mathrm{Vr}$ as described in section 3 was tested on different datasets flying over land and water. Examples are presented from the Nor'easter, CSET, and SOCRATES experiments. The two-stage filter process with the same FIR filters was used in the entire Nor'easter and CSET field programs including the examples shown. The SOCRATES correction used a single regression filter. Statistics computed over the entire flights are then presented. Keep in mind that in these data, positive Vrindicates downward motion.

\section{a. Nor'easter examples}

Two Nor'easter examples were chosen to include one over land and one over ocean. The results of these examples are typical of the entire flight. 

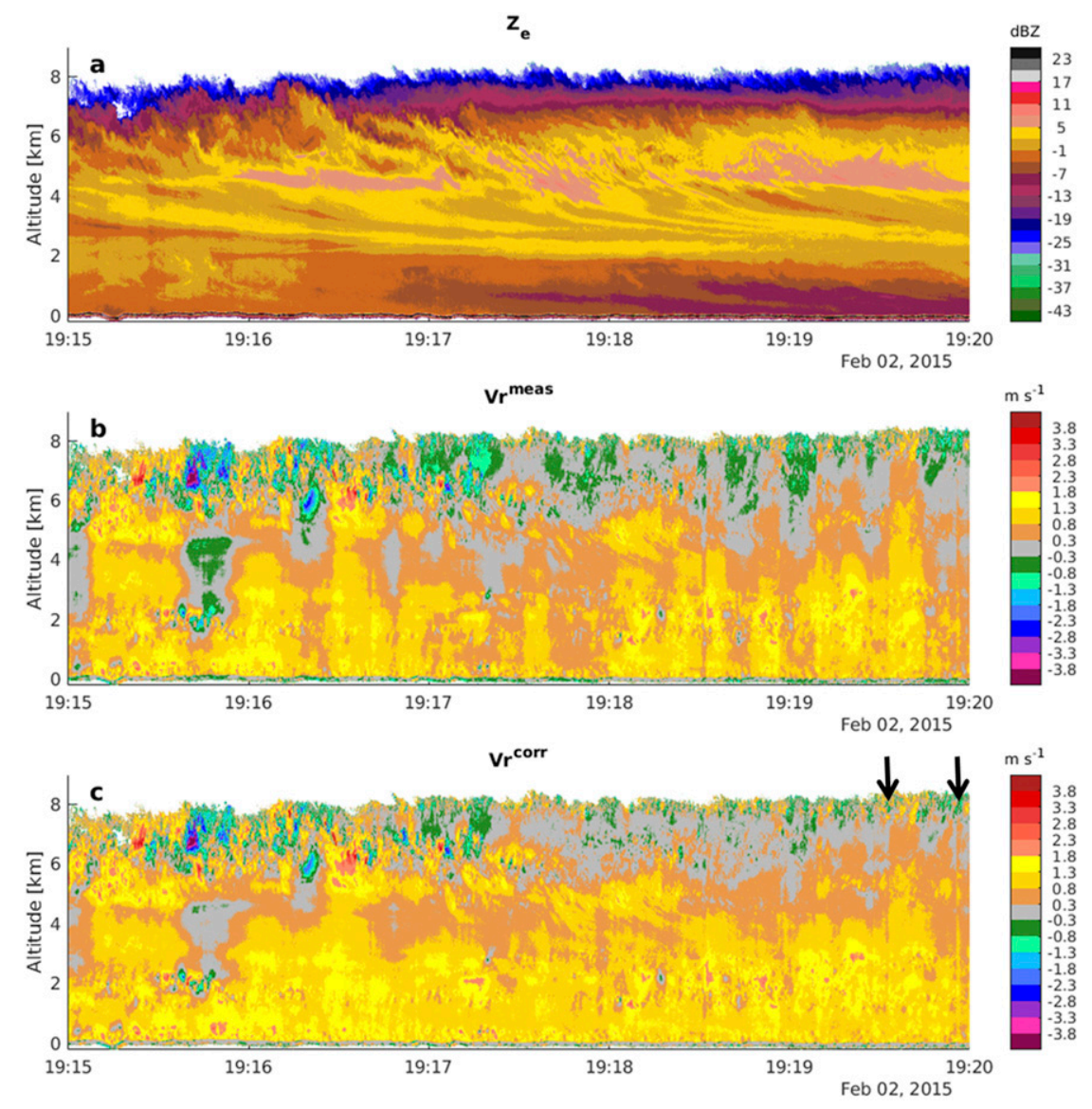

FIG. 3. Time-height plots of (a) Ze, (b) $\mathrm{Vr}^{\text {meas }}$, and (c) $\mathrm{Vr}^{\text {corr }}$ observed during Nor'easter from 1915 to 1920 UTC 2 Feb 2015. The data were taken over land.

Figures $3 \mathrm{a}-\mathrm{c}$ show height versus time plots of the $\mathrm{Ze}$, $\mathrm{Vr}^{\text {meas }}$, and $\mathrm{Vr}^{\text {corr }}$ after the surface-reference correction observed during Nor'easter from 1915 to 1920 UTC 2 February 2015. This is the same dataset presented in Figs. 1 and 2. The radar was flying over land at this time. The $\mathrm{Vr}^{\text {meas }}$ term shown in Fig. $3 \mathrm{~b}$ has been corrected for the measured pointing angles and platform vertical motion following Lee et al. (1994). However, it can be seen that the variable pointing errors (described in section $3 b$ ) show up as columns, or pillars, of alternately higher and lower Vr values with a period of about $15-45 \mathrm{~s}$. Comparing $\mathrm{Vr}_{\text {surf }}^{\text {meas }}$ in Fig. 1 to the $\mathrm{Vr}^{\text {meas }}$ field in Fig. 3b, it can be seen that the pillars of elevated $\mathrm{Vr}$ values are in the same location as the elevated values of $\mathrm{Vr}_{\text {surf }}^{\text {meas }}$.

After applying the surface-reference correction, the pillars of $\mathrm{Vr}$ errors are largely removed. There are some very narrow vertical features appearing in both Figs. 3b and 3c, for example shortly before 1920 UTC marked by the black arrows in Fig. 3c. These are likely due to flight-level turbulence and cannot be corrected using the surface-reference technique.
Figure 4 shows the surface $\mathrm{Vr}$ after the surface-based correction was applied $\left(\mathrm{Vr}_{\text {surf }}^{\text {corr }}\right)$. The term $\mathrm{Vr}_{\text {surf }}^{\text {corr }}$ is $\mathrm{Vr}_{\text {surf }}^{\text {meas }}$ after subtracting the $\mathrm{Vr}_{\text {surf }}^{\text {filt }}$ and thus should contain all of the independent surface $\mathrm{Vr}$ errors, but not show the systematic errors. It can be seen that $\mathrm{Vr}_{\text {surf }}^{\text {corr }}$ is centered at $0 \mathrm{~m} \mathrm{~s}^{-1}$ indicating the systematic error has been removed.

To verify the correction technique and to quantify its performance, we computed the mean and variance of $\mathrm{Vr}_{\text {surf }}^{\text {corr }}$ for the data shown in Fig. 4 after the surface anomalies as identified above were removed from the dataset. The variance of the remaining data represents the combined random measurement error and the error of the surface-reference correction. Any errors in $\mathrm{Vr}^{\text {meas }}$ introduced or left uncorrected by the technique would add to the measured variance. The mean was $-0.004 \mathrm{~m} \mathrm{~s}^{-1}$ and the variance turned out to be $0.008 \mathrm{~m}^{2} \mathrm{~s}^{-2}$. The estimated variance of $\mathrm{Vr}$ for the radar operating wavelength, pulse repetition time, and the mean measured surface spectrum width of $0.7 \mathrm{~m} \mathrm{~s}^{-1}$ was estimated to be $0.0015 \mathrm{~m}^{2} \mathrm{~s}^{-2}$ using Eq. (6.23) from Doviak and Zrnić (1993). The theoretical 


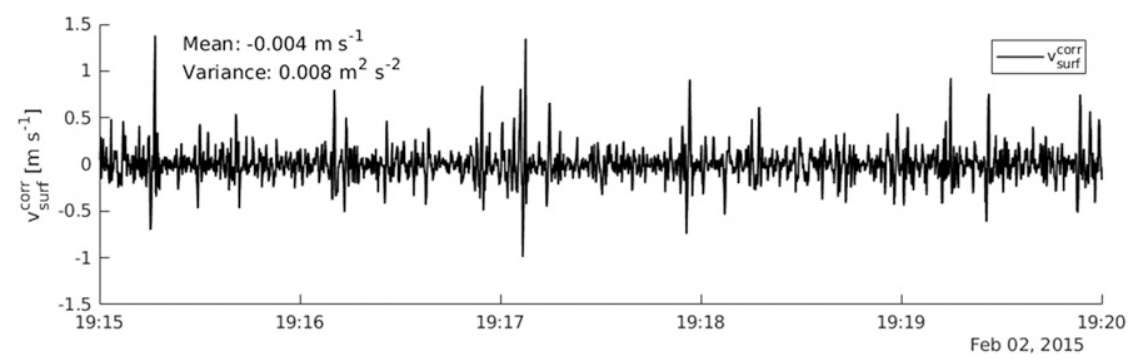

FIG. 4. Time series of $\mathrm{Vr}_{\text {surf }}^{\text {corr }}$ corresponding to the data shown in Figs. 1 and 2. The mean of $\mathrm{Vr}_{\text {surf }}^{\text {corr }}$ is $-0.004 \mathrm{~m} \mathrm{~s}^{-1}$ and the variance is $0.008 \mathrm{~m}^{2} \mathrm{~s}^{-2}$.

variance calculation assumes uniform $\mathrm{Ze}$ across the beam, which is not strictly true. However, in this stratiform snow case the Ze gradients are not very high at the scale of the HCR resolution, as might be expected in convective precipitation.

The difference between the theoretical variance and the computed variance for this data is $0.0065 \mathrm{~m}^{2} \mathrm{~s}^{-2}$, which can be interpreted as the upper bound for the variance added by the correction technique for this dataset.

We also computed the average of $\mathrm{Vr}^{\text {meas }}$ and $\mathrm{Vr}^{\text {corr }}$ along each vertical beam in Fig. 3 resulting in 2959 mean $\mathrm{Vr}$ values over the $5 \mathrm{~min}$ of data. The variance of the beam-averaged $\mathrm{Vr}^{\mathrm{meas}}$ was $0.23 \mathrm{~m}^{2} \mathrm{~s}^{-2}$ and the variance for $\mathrm{Vr}^{\text {corr }}$ was $0.035 \mathrm{~m}^{2} \mathrm{~s}^{-2}$ representing a reduction of a factor of 6.5 after the surface-reference correction. It is encouraging that the variance of the beam-averaged $\mathrm{Vr}^{\mathrm{corr}}$ is substantially reduced after the surface-reference correction. This is most likely due to the correction of the velocity pillar errors.

The data shown in Fig. 3 are from the cold sector of the storm and consists of frozen precipitation throughout. It is interesting to note some of the features in the $\mathrm{Vr}^{\text {corr }}$ field shown in Fig. 3c. There are many generating cells near the top of the echo as seen by the updrafts (negative $\mathrm{Vr}$ values). There are several updraft and downdraft pairs that are of approximately the same magnitude, as would be expected. Generating cells were commonly observed during the Nor'easter flight (Rauber et al. 2017). The fall speed of the precipitation increases with decreasing altitude from less than 1 to around $1.5 \mathrm{~m} \mathrm{~s}^{-1}$ near the surface, consistent with aggregating ice (Rauber et al. 2017).

The second Nor'easter example is from data collected while flying over the ocean off of the East Coast of the United States from 1405 to 1410 UTC. Figure 5a shows the $\mathrm{Ze}$ for this case. The surface can again be seen as the high values of $Z$ e at $0-\mathrm{km}$ altitude. The surface reflection over the water is flat as opposed to the surface echo over land in Fig. 3. Figure 5b shows the $\mathrm{Vr}^{\text {meas }}$, which once again shows erroneous pillars of elevated and reduced Vr values due to pointing-angle errors.
The plot of $\mathrm{Vr}_{\text {surf }}^{\text {meas }}$ in Fig. 5b shows mostly negative (green) values. The mean $\mathrm{Vr}_{\text {surf }}^{\text {meas }}$ is $-0.56 \mathrm{~m} \mathrm{~s}^{-1}$ translating into an along-track pointing error of $0.12^{\circ}$ given the mean ground speed of $278 \mathrm{~m} \mathrm{~s}^{-1}$. This systematic pointing error is due to the drift of the INS/GPS measured attitude of the platform over time. A few minutes after the data in Fig. 5 were taken, the airplane turned around at the northern end of the flight track. The turn created accelerations that resulted in the INS/GPS unit improving the attitude accuracy. The mean $\mathrm{Vr}_{\text {surf }}^{\text {meas }}$ after the turn, from 1425 to 1430 UTC, was just $-0.01 \mathrm{~m} \mathrm{~s}^{-1}$, representing an along-track error of only $0.003^{\circ}$ given the mean ground speed of $208 \mathrm{~m} \mathrm{~s}^{-1}$.

After the surface-reference correction was applied, the pillars of erroneous $\mathrm{Vr}$ are removed and do not appear in $\mathrm{Vr}^{\text {corr }}$ (Fig. 5c). Also the systematic Vr error from the drift in the accuracy of the INS/GPS unit has been removed as evidenced by the surface velocity that is between near $0 \mathrm{~m} \mathrm{~s}^{-1}$ (gray color).

\section{b. CSET example}

The next example results are from the CSET field program from 1739 to 1744 UTC 17 July 2015. The data were collected over the ocean en route from Sacramento, California, to Kona, Hawaii. The HIAPER was flying at about $1.8 \mathrm{~km}$ above sea level at approximately $158 \mathrm{~m} \mathrm{~s}^{-1}$ over a field of stratocumulus clouds. The example was chosen because it was typical of the correction results and illustrated the importance of removing small biases. The reflectivity shown in Fig. 6a shows vertically oriented features indicating drizzle that has formed in the cloud system and has been detected reaching the surface in some locations. The surface echo is shown by the band of high $\mathrm{Ze}$ values near 0-km altitude in Fig. 6a. The surface echo in this example is the same thickness as in the Nor'easter data, but appears larger due to the condensed vertical scale of the plot. The values of $\mathrm{Vr}$ in the surface echo are mostly negative (green color) and the mean was $-0.18 \mathrm{~m} \mathrm{~s}^{-1}$, indicating a mean along-track pointing error of $0.065^{\circ}$. This small error is close to the stated accuracy of the SDN-500 INS/GPS system used by HCR. 

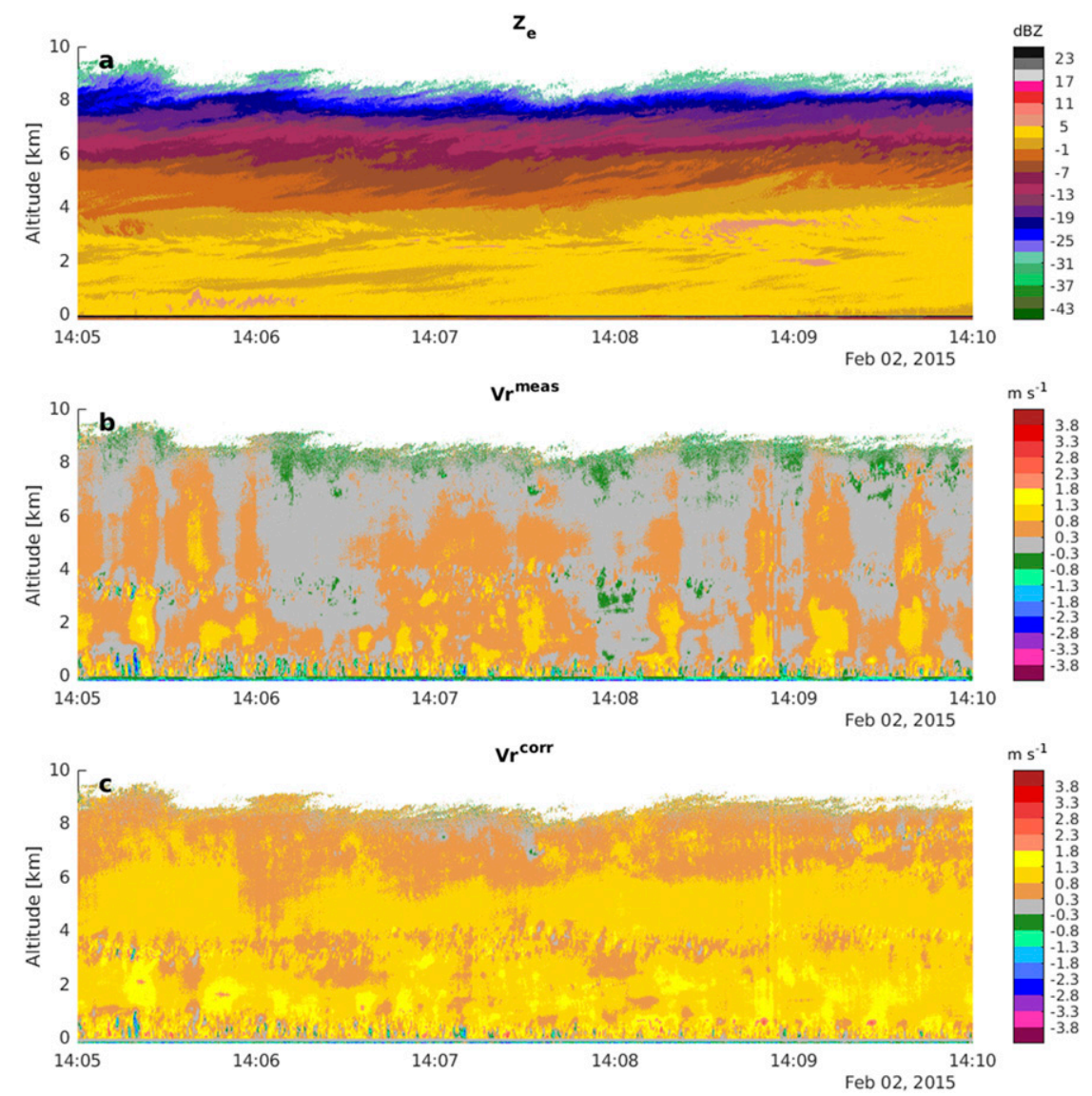

FIG. 5. Time-height plots of (a) Ze, (b) $\mathrm{Vr}^{\text {meas }}$, and (c) $\mathrm{Vr}^{\text {corr }}$ observed during Nor'easter from 1400 to 1415 UTC 2 Feb 2015. The data were taken over water.

The $\mathrm{Vr}_{\text {surf }}^{\text {meas }}$ in this case (Fig. 7a) shows that the variable $\mathrm{Vr}$ errors (section 3b) are still present, but have a much reduced amplitude, largely due to improved gears installed after the Nor'easter project. The magnitude of the variable $\mathrm{Vr}$ errors is about $\pm 0.3 \mathrm{~m} \mathrm{~s}^{-1}$ or so. It is difficult to determine how much of the variable $\mathrm{Vr}$ errors are due to changing pointing errors and how much are due to vertical velocity errors from the INS/GPS unit, which is about $0.1 \mathrm{~m} \mathrm{~s}^{-1}$ according to the INS/GPS manufacturer.

Examining $\mathrm{Vr}^{\text {corr }}$ shown in Fig. 6c indicates that the surface-reference correction removed the mean bias in $\mathrm{Vr}^{\text {meas }}$. The mean of $\mathrm{Vr}_{\text {surf }}^{\text {corr }}$ (Fig. 7b) is $0.00 \mathrm{~m} \mathrm{~s}^{-1}$ and the oscillations due to the variable $\mathrm{Vr}$ error have been removed. The overall $\mathrm{Vr}^{\text {corr }}$ field does not show the widespread negative values apparent in Fig. $6 \mathrm{~b}$ that erroneously indicated updrafts at the top of the echoes. This changes the interpretation of the data substantially even though the magnitude of the correction is quite small in this case. This example highlights that the desired accuracy for vertical pointing radars is very high because even errors on the order of tenths of a meter per second constitute large relative errors for measuring updrafts and particle fall speeds.

\section{c. SOCRATES examples}

Two SOCRATES examples are presented. The first illustrates a successful correction typical of most of the data collected. The second SOCRATES example shows a time period when large ocean waves created errors in $\mathrm{Vr}^{\text {corr }}$. These examples used the regression filter described in section $3 b(5)$ rather than the two-stage FIR filters used in the previous examples.

The first example from SOCRATES comes at 2305 UTC 22 January 2018 when the HIAPER aircraft was flying at about $5-\mathrm{km}$ altitude. The aircraft was relatively close to Tasmania at this time where large waves were not common. Figure 8 shows the reflectivity, $\mathrm{Vr}^{\text {meas }}$, and $\mathrm{Vr}^{\text {corr }}$. The $\mathrm{Vr}^{\text {meas }}$ plot shows some vertical $\mathrm{Vr}$ pillars that are likely from the variable $\mathrm{Vr}$ errors. This is consistent with $\mathrm{Vr}_{\text {surf }}^{\text {meas }}$ for this case shown in Fig. 9a which shows some oscillations with a period of about $20-30 \mathrm{~s}$ and an amplitude of about $0.3-0.5 \mathrm{~m} \mathrm{~s}^{-1}$. 

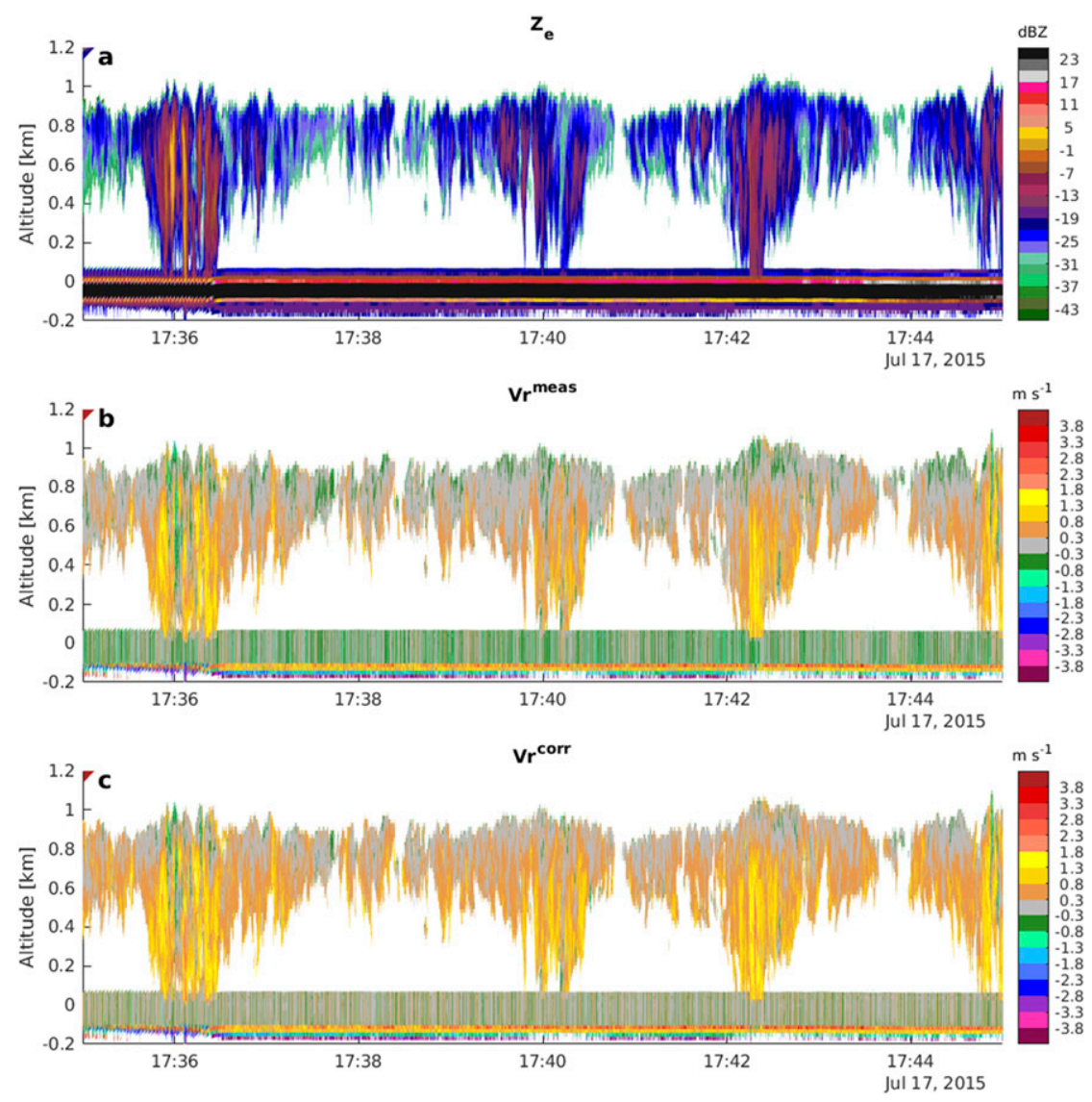

FIG. 6. Time-height plots of (a) Ze, (b) $\mathrm{Vr}^{\text {meas }}$, and (c) Vr ${ }^{\text {corr }}$ observed during CSET from 1735 to 1745 UTC 17 Jul 2015. The data were taken over water.

From $\mathrm{Vr}_{\text {surf }}^{\text {corr }}$, shown in Fig. 9b, it can be seen that these oscillations have been reduced. It can also be seen that the negative bias in $\mathrm{Vr}_{\text {surf }}^{\text {meas }}$ has been removed. In this case the mean of $\mathrm{Vr}_{\text {surf }}^{\text {meas }}$ was $-0.28 \mathrm{~m} \mathrm{~s}^{-1}$ and the mean of $\mathrm{Vr}_{\text {surf }}^{\text {corr }}$ was $0.00 \mathrm{~m} \mathrm{~s}^{-1}$. Comparing $\mathrm{Vr}^{\text {meas }}$ and $\mathrm{Vr}^{\text {corr }}$ in
Figs. $8 \mathrm{~b}$ and $8 \mathrm{c}$, it can be seen that the velocity pillars in $\mathrm{Vr}^{\text {meas }}$ were reduced by the surface-based $\mathrm{Vr}$ correction. The second SOCRATES example is from the same flight shown in Figs. 8 and 9 but at 0150 UTC 23 January 2018. Figure 10 shows the reflectivity, $\mathrm{Vr}^{\text {meas }}$, and $\mathrm{Vr}^{\text {corr }}$.
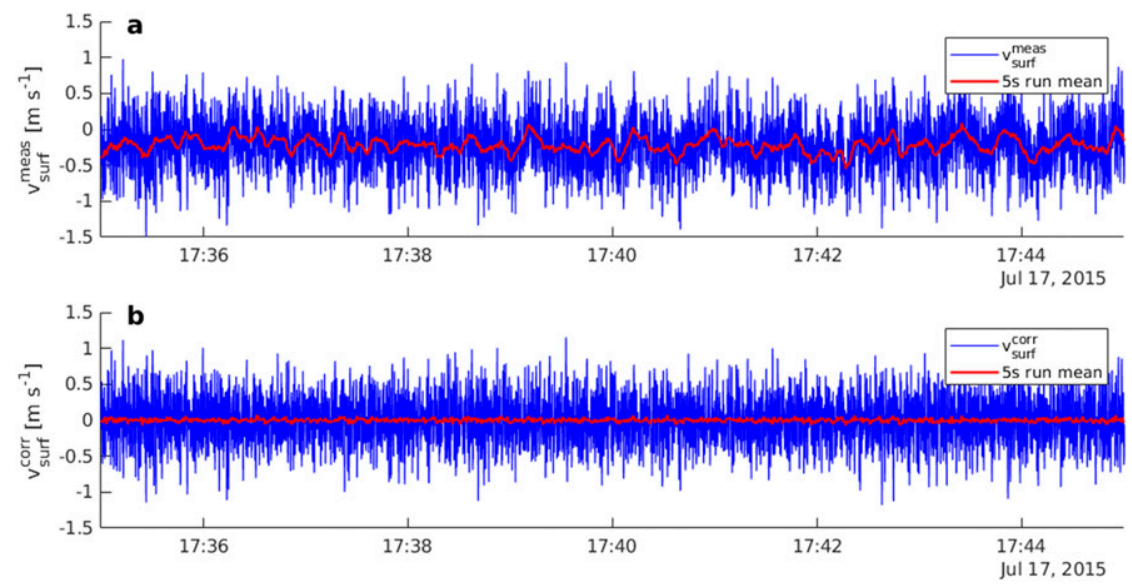

FIG. 7. Times series of (a) $\mathrm{Vr}_{\text {surf }}^{\text {meas }}$ and (b) $\mathrm{Vr}_{\text {surf }}^{\text {corr }}$ (blue) corresponding to the CSET data shown in Fig. 6. The red lines indicate a 5-s running mean of the plotted data. 

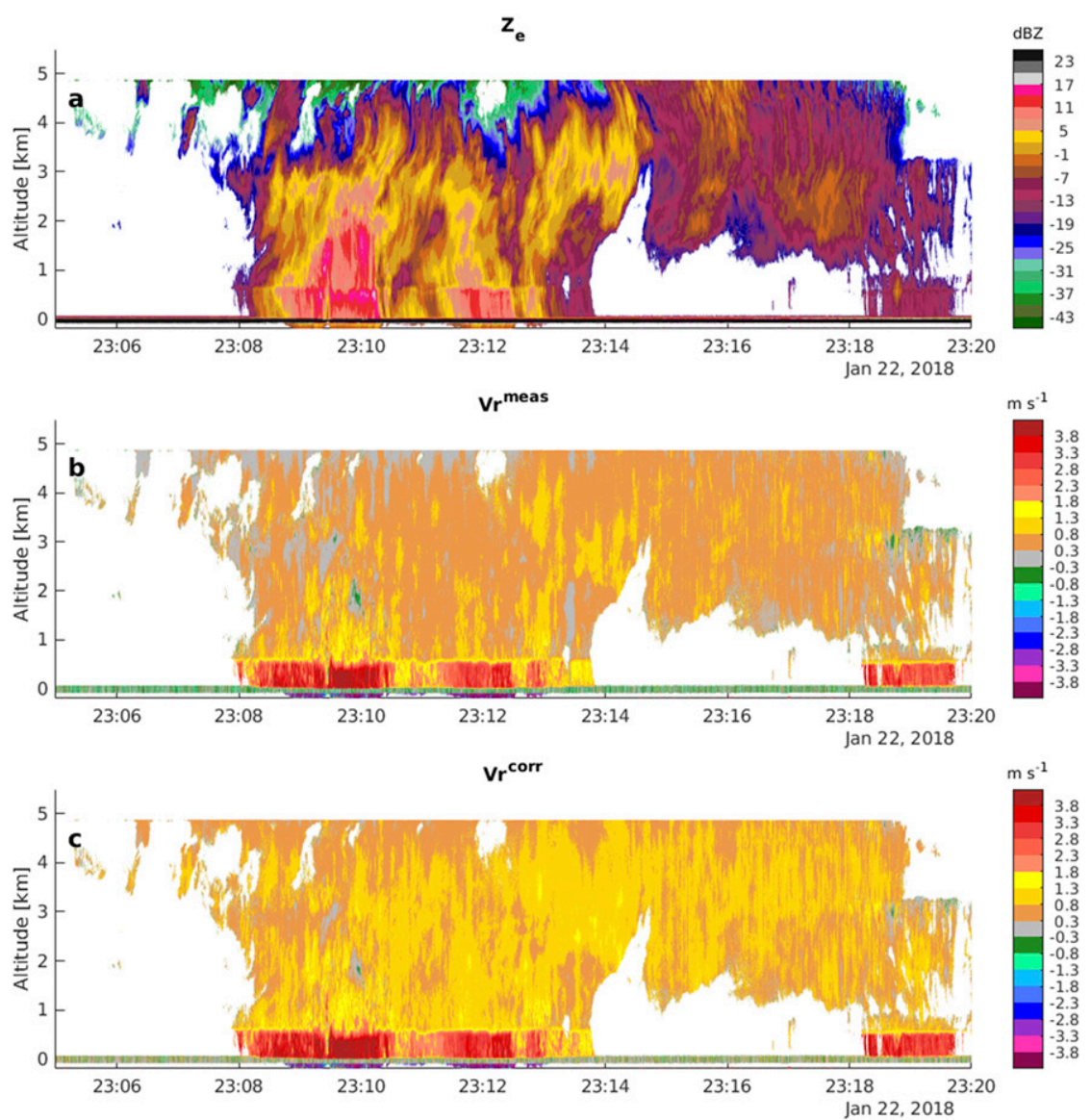

FIG. 8. Time-height plots of (a) Ze, (b) $\mathrm{Vr}^{\text {meas }}$, and (c) $\mathrm{Vr}^{\text {corr }}$ observed during SOCRATES from 2305 to 2320 UTC 22 Jan 2018. The data were taken over water.

The aircraft was flying at only 3-km altitude and was in the open ocean where large waves are common. The mean of $\mathrm{Vr}_{\text {surf }}^{\text {meas }}$ is $0.23 \mathrm{~m} \mathrm{~s}^{-1}$ in this case, and the mean of $\mathrm{Vr}_{\text {surf }}^{\text {corr }}=0.003 \mathrm{~m} \mathrm{~s}^{-1}$ indicates that the surface-reference correction removed the bias. This is evident comparing Figs. 11a and $11 \mathrm{~b}$.

In this example, however, a few suspicious-looking $\mathrm{Vr}$ pillars appear after the surface-based correction is made
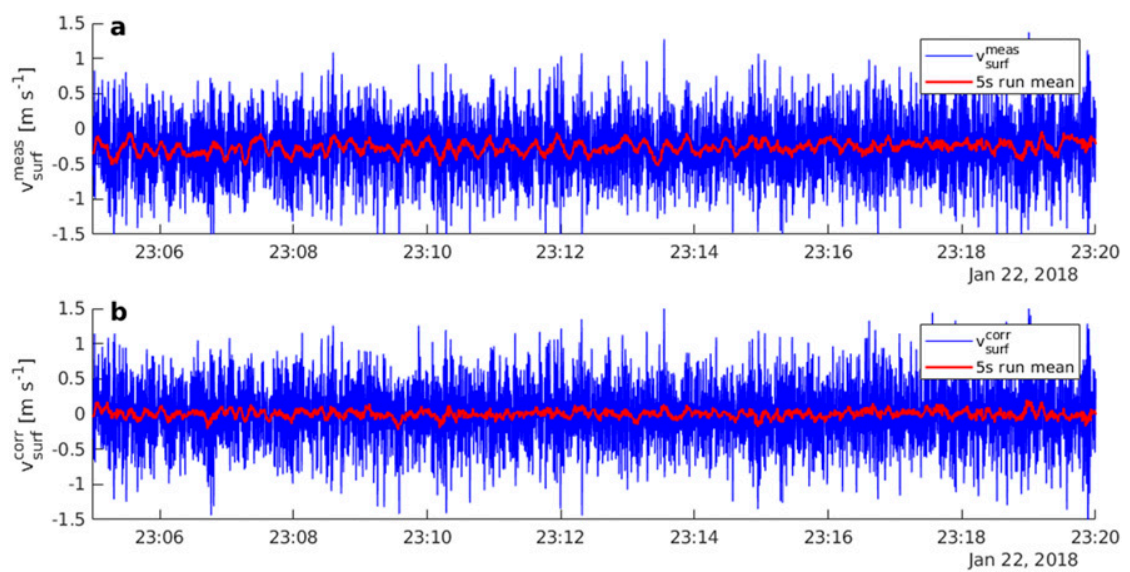

FIG. 9. Time series of (a) $\mathrm{Vr}_{\text {surf }}^{\text {meas }}$ and(b) $\mathrm{Vr}_{\text {surf }}^{\text {corr }}$ (blue) corresponding to the SOCRATES data shown in Fig. 8. The red lines indicate a $5 \mathrm{~s}$ running mean of the plotted data. 

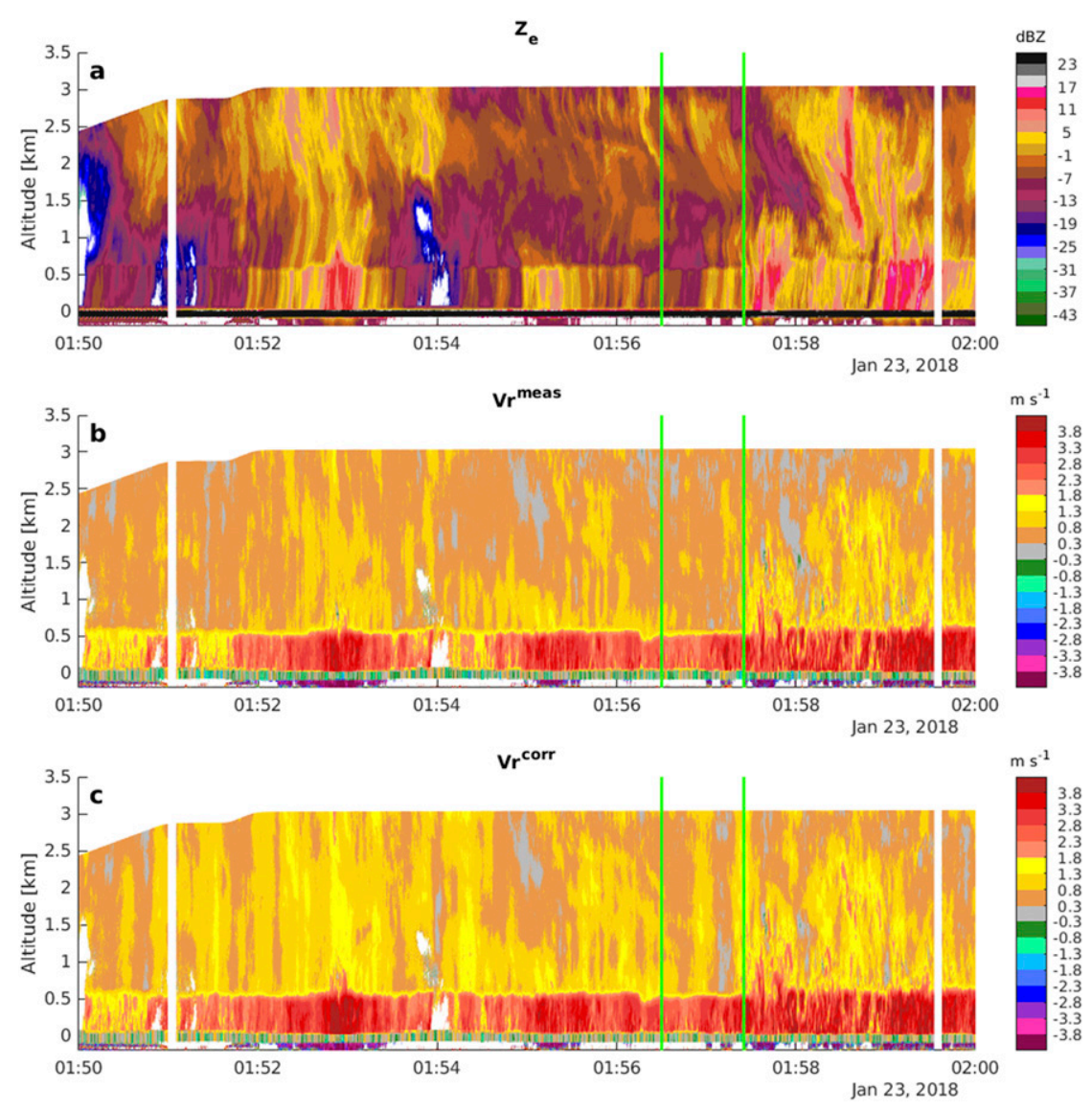

FIG. 10. Time-height plots of (a) Ze, (b) $\mathrm{Vr}^{\text {meas }}$, and (c) $\mathrm{Vr}^{\text {corr }}$ observed during SOCRATES from 0150 to 0200 UTC 23 Jan 2018. The data were taken over water.

and these pillars are not associated with Ze features that would help explain them due to differing fall speeds. It also seems unlikely that vertical air motions can explain the pillars that extend throughout the vertical extent of the echo. The cause is most likely large ocean waves with nonzero vertical velocity when integrated over the radar beam footprint [see also section $3 b(5)$ ]. This is illustrated by examining the $\mathrm{Vr}$ pillars in Fig. 10c around 0157 UTC demarked by the vertical green lines and comparing them to the same time in Fig. 11a showing the $\mathrm{Vr}_{\text {surf }}^{\text {meas }}$, also demarked by vertical lines. The red line in Fig. 11a shows the $5 \mathrm{~s}$ mean filter of $\mathrm{Vr}_{\text {surf }}^{\text {meas }}$ plotted for clarity. Right at 0157 UTC there is a negative deviation from the mean of approximately $0.5 \mathrm{~m} \mathrm{~s}^{-1}$, which is surrounded by positive deviations of about the same magnitude evident in Fig. 11a. These features are removed from the $\mathrm{Vr}_{\text {surf }}^{\text {meas }}$ by the regression filter as can be seen in Fig. 11b, indicating that these $\mathrm{Vr}$ deviations were subtracted from $\mathrm{Vr}^{\text {meas }}$ to obtain $\mathrm{Vr}^{\text {corr }}$. The impact is that $\mathrm{Vr}^{\text {corr }}$ shows erroneous values opposite in sign and similar in magnitude in Fig. 10c to the Vr deviations from the mean seen in
Fig. 11a. This is consistent with subtracting the real motion of the surface due to ocean waves from the $\mathrm{Vr}$ data at all ranges.

\section{d. Statistics for full flights}

To evaluate the overall performance of the surfacebased correction method, statistics of the nadir pointing data over the course of the flights presented above were computed. The Nor'easter flight included six $840-\mathrm{km}$ transects between northern Delaware and Bangor, Maine, with HCR in nadir pointing for the entire 7-h mission. The CSET flight was from California to Hawaii on 17 July 2015 with a nearly 7-h duration. The HIAPER aircraft flew both above and below the clouds and HCR was operated in nadir and zenith pointing accordingly, with approximately $240 \mathrm{~min}$ of nadir-pointing data. The SOCRATES flight took place on 22 January 2018 with a duration of $7 \mathrm{~h} 15 \mathrm{~min}$ including approximately $230 \mathrm{~min}$ of nadir data. The two-stage filter process using the same FIR filters were used for Nor'easter and CSET and a single-stage regression filter was used for the SOCRATES data. 

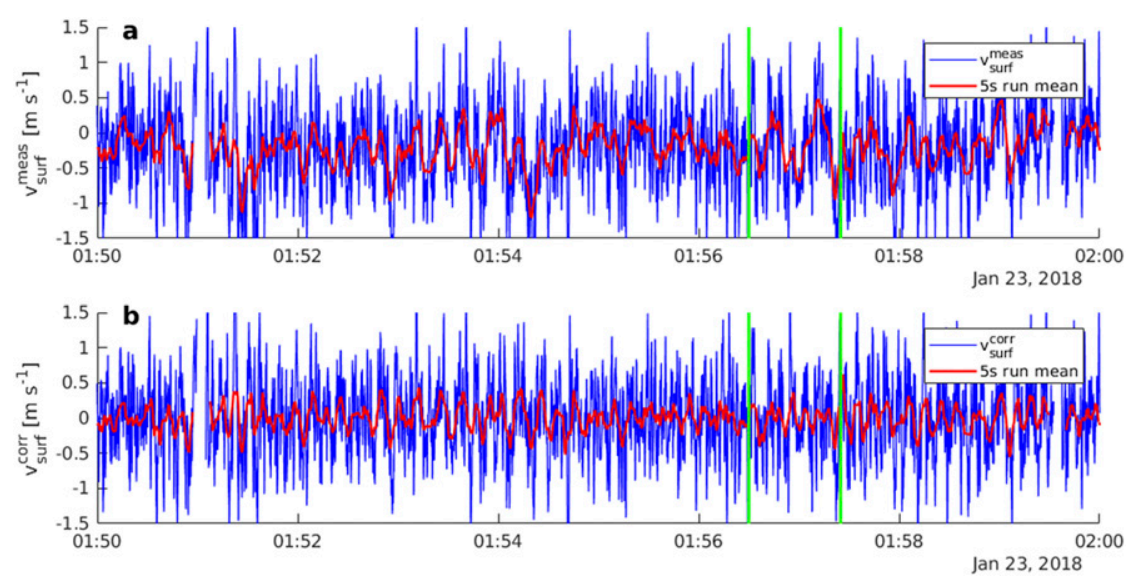

FIG. 11. Time series of (a) $\mathrm{Vr}_{\text {surf }}^{\text {meas }}$ and (b) $\mathrm{Vr}_{\text {surf }}^{\text {corr }}$ (blue) corresponding to the SOCRATES data shown in Fig. 10. The red line denotes the 5-s running mean of surface Vr.

Table 1 shows the mean values of $\mathrm{Vr}_{\text {surf }}^{\text {corr }}$ and $\mathrm{Vr}_{\text {surf }}^{\text {meas }}$ for the three flights. The magnitude of the mean bias in $\mathrm{Vr}_{\text {surf }}^{\text {meas }}$ ranged from 0.07 to $0.2 \mathrm{~m} \mathrm{~s}^{-1}$. It can be seen that the overall bias in surface $\mathrm{Vr}$ was removed in all three cases.

Table 2 shows the variance (var) of $\mathrm{Vr}_{\text {surf }}^{\text {corr }}$ and $\mathrm{Vr}_{\text {surf }}^{\text {meas }}$ as well as the ratio $\operatorname{var}\left(\mathrm{Vr}_{\text {surf }}^{\text {meas }}\right) / \operatorname{var}\left(\mathrm{Vr}_{\text {surf }}^{\text {corr }}\right)$ for the three flights. All three flights show a reduction of the variance of surface $\mathrm{Vr}$ after the correction with Nor'easter exhibiting the largest reduction by a considerable amount. This is not surprising since the variable $\mathrm{Vr}$ errors were far greater for Nor'easter than for the other two projects that occurred after the gears controlling the reflector pointing were replaced. The reduction in the variance of $\mathrm{Vr}_{\text {surf }}^{\text {corr }}$ compared to $\mathrm{Vr}_{\text {surf }}^{\text {meas }}$ was greater for CSET than for SOCRATES even though the variable $\mathrm{Vr}$ errors were similar. This is probably due to the additional errors from the nonstationary large ocean waves in the Southern Ocean causing some errors in the SOCRATES data. It is worth noting that the surface based correction resulted in a $15 \%$ reduction in the variance indicating a substantial improvement in the Vr estimate overall.

The radial means $\mathrm{Vr}_{\text {surf }}^{\text {meas }}$ and $\mathrm{Vr}_{\text {surf }}^{\text {corr }}$ were computed $\left(\mathrm{Vr}_{\mathrm{rmean}}^{\text {meas }}\right.$ and $\mathrm{Vr}_{\mathrm{rmean}}^{\mathrm{corr}}$, respectively), which included data from the first valid range gate to the surface of each radar dwell. The variance of these time series of radial means along with the ratios $\operatorname{var}\left(\mathrm{Vr}_{\text {rmean }}^{\text {meas }}\right) / \operatorname{var}\left(\operatorname{Vr}_{\mathrm{rmean}}^{\text {corr }}\right)$ are listed in Table 3. It can be seen that the variance was reduced considerably for both Nor'easter and CSET (65\% and $47 \%$, respectively) and for SOCRATES there was a $7 \%$ reduction.

This analysis shows that the overall mean biases were largely removed and the variance of $\mathrm{Vr}$ was reduced overall after application of the surface-based Vr correction.

\section{Summary and conclusions}

A new, simple correction technique for $\mathrm{Vr}$ from nadir-looking airborne radars using the surface echo as a reference was proposed and tested. The method filters the measured surface Vr using either a FIR or polynomial regression filter to remove variations in $\mathrm{Vr}_{\text {surf }}^{\text {meas }}$ that only impact the surface echo while fitting systematic variations that are seen at all ranges. The filtered surface $\mathrm{Vr}$ is then subtracted from the measured $\mathrm{Vr}$ in all range bins. The use of a two-stage filtering process was developed to remove large $\mathrm{Vr}_{\text {surf }}^{\text {meas }}$ deviations that result in the moving radar with a finite beamwidth passing over small local maxima in Ze. It was found to be required over land, where these deviations are common, in order to obtain usable, corrected Vr measurements.

The method was applied to data from three field programs including Nor'easter, CSET, and SOCRATES and resulted in substantial improvements in the quality of the Vr field. Errors from the variable pointing error, any residual pointing bias, and pointing errors due to drift in the INS/GPS measurements were all largely removed. Further, the variance of the $\mathrm{Vr}_{\text {surf }}^{\mathrm{corr}}$ and the variance of the radial mean of the overall $\mathrm{Vr}^{\text {corr }}$, which were about the same magnitude as the bias, were substantially reduced for all three datasets. This reduction in variance is most likely due to the mitigation of the

TABLE 1. Mean values of the surface $\mathrm{Vr}$ after using the surface correction $\left(\mathrm{Vr}_{\text {surf }}^{\text {corr }}\right)$ and without the surface correction $\left(\mathrm{Vr}_{\text {surf }}^{\text {meas }}\right)$ for flights from Nor'easter, CSET, and SOCRATES.

\begin{tabular}{lcc}
\hline \hline & Mean of $\mathrm{Vr}_{\text {surf }}^{\text {corr }}\left(\mathrm{m} \mathrm{s}^{-1}\right)$ & Mean of $\mathrm{Vr}_{\text {surf }}^{\text {meas }}\left(\mathrm{m} \mathrm{s}^{-1}\right)$ \\
\hline Nor'easter & 0.00 & -0.20 \\
CSET & -0.01 & 0.07 \\
SOCRATES & 0.00 & -0.16 \\
\hline
\end{tabular}


TABLE 2. Variance values of the surface Vr after using the surface correction $\left(\mathrm{Vr}_{\text {surf }}^{\text {corr }}\right)$ and without the surface correction $\left(\mathrm{Vr}_{\text {surf }}^{\text {meas }}\right)$. Also included are the ratios $\operatorname{var}\left(\mathrm{Vr}_{\text {surf }}^{\text {meas }}\right) / \operatorname{var}\left(\mathrm{Vr}_{\text {surf }}^{\text {corr }}\right)$.

\begin{tabular}{lccc}
\hline \hline & $\begin{array}{c}\text { Variance of } \mathrm{Vr}_{\text {surf }}^{\text {corr }} \\
\left(\mathrm{m}^{2} \mathrm{~s}^{-2}\right)\end{array}$ & $\begin{array}{c}\text { Variance of } \mathrm{Vr}_{\text {surf }}^{\text {meas }} \\
\left(\mathrm{m}^{2} \mathrm{~s}^{-2}\right)\end{array}$ & Ratio \\
\hline Nor'easter & 0.089 & 0.21 & 2.36 \\
CSET & 0.17 & 0.26 & 1.53 \\
SOCRATES & 0.19 & 0.22 & 1.15 \\
\hline
\end{tabular}

time-variable errors in $\mathrm{Vr}$ due to pointing and platform motion errors that changed in time. Also, it was seen that errors were not introduced into the data by measurement variations in $\mathrm{Vr}_{\text {surf }}^{\text {meas }}$ in the Nor'easter and CSET datasets indicating that the filter process was effective. It is interesting to note that even small corrections could dramatically change the interpretation of the data as regions of erroneously identified updrafts are corrected.

In the case of SOCRATES the assumption of a stationary surface was sometimes violated. This posed a very challenging problem when the period of the oscillations due to large ocean waves were similar to the variable $\mathrm{Vr}$ errors due to pointing or vertical velocity measurement errors. This is because the oscillations due to ocean waves need to be removed by the filter while the oscillations due to the variable Vr error need to be fit by the filter. When the two oscillations are similar in scale, there is no one filter that can accomplish this. Methods are currently being investigated to objectively identify the different variations in $\mathrm{Vr}_{\text {surf }}^{\text {meas }}$ and then filter them appropriately. Options include taking into account the location of the aircraft to determine if large ocean waves are likely to be observed and the altitude of the aircraft, which determines the radar surface footprint. Data with smaller radar footprints at lower altitudes were more susceptible to contamination by ocean waves.

The three examples presented here illustrate that different datasets may have different challenges for $\mathrm{Vr}$ correction. The filters that worked for Nor'easter and CSET were not the best choice for SOCRATES. Other challenges could arise from changes in how the HCR processes data that may result in different measurement variances and characteristics. Although it is difficult to quantify exactly without verification data, based on the analysis presented we are confident that the surfacereference corrected $\mathrm{Vr}$ data has a mean bias that is very close to $0 \mathrm{~m} \mathrm{~s}^{-1}$. Also, the variance in $\mathrm{Vr}$ has been substantially reduced by the correction indicating that the variable errors due to pointing and platform motion errors have been largely mitigated. Since the measurement variance of $\mathrm{Vr}$ depends on echo characteristics
TABLE 3. Variance values of the radial means of the surfacecorrected $\operatorname{Vr}\left(\mathrm{Vr}_{\text {rmean }}^{\text {corr }}\right)$ and without the surface correction $\left(\mathrm{Vr}_{\text {rmean }}^{\text {meas }}\right)$. Also included are the ratios $\operatorname{var}\left(\mathrm{Vr}_{\mathrm{rmean}}^{\text {meas }}\right) / \operatorname{var}\left(\mathrm{Vr}_{\mathrm{rmean}}^{\text {corr }}\right)$.

\begin{tabular}{lccc}
\hline \hline & $\begin{array}{c}\text { Variance of } \mathrm{Vr}_{\text {rmean }}^{\text {corr }} \\
\left(\mathrm{m}^{2} \mathrm{~s}^{-2}\right)\end{array}$ & $\begin{array}{c}\text { Variance of } \mathrm{Vr}_{\text {rmean }}^{\text {meas }} \\
\left(\mathrm{m}^{2} \mathrm{~s}^{-2}\right)\end{array}$ & Ratio \\
\hline Nor'easter & 0.23 & 0.38 & 1.65 \\
CSET & 0.15 & 0.22 & 1.47 \\
SOCRATES & 0.24 & 0.26 & 1.07 \\
\hline
\end{tabular}

including spectrum width and signal to noise ratio as well as the radar itself, it will vary from case to case, but is estimated to be between about 0.1 and $0.25 \mathrm{~m}^{2} \mathrm{~s}^{-2}$ for the cases presented. It is important to keep in mind that the errors from the horizontal wind leaking into the data at slightly off-nadir pointing angles are not corrected by this method. The real-time beam-pointing stabilization of HCR is deployed in order to minimize those wind errors. Vivekanandan et al. (2015) found that the beam remained within about $0.1^{\circ}$ of nadir, resulting in only very small errors from the horizontal wind.

The approach is generally applicable to nadir-pointing airborne radar data, but may require changes based on the radar parameters being used and the type of terrain that is being overflown. For example, the value of the threshold used to determine where to apply the first stage filter should be approximately twice the standard deviation of $\mathrm{Vr}_{\text {surf }}^{\text {meas }}$ due to measurement uncertainties of the radar resulting from its operating parameters as well as any other contribution such as the effects of nonuniform surface echoes and low signal to noise ratio. This will ensure that the stage 1 filter process only removes the large deviations of $\mathrm{Vr}_{\text {surf }}^{\text {meas }}$.

Another adjustment that may need to be made to apply this method in different situations is the filter response of the stage 1 and stage 2 filters. It is worth examining the data to be corrected to determine which oscillations, if any, need to be fitted and which need to be filtered out. Then one can design the proper filters.

Like all algorithms, the surface-reference correction for $\mathrm{Vr}$ will have failure modes, including surface misclassifications and nonstationary surface echoes. The surface misclassifications are mitigated by only searching in the nearest $1 \mathrm{~km}$. This number is quite conservative and we are investigating how small we can reasonably make this limit (perhaps $100 \mathrm{~m}$ ). Other quality-control (QC) criteria are also being investigated with the goal of flagging potential errors in the correction. These include examining the continuity of the correction and flagging large, sudden changes as well as flagging data with very large corrections that exceed expectations. Work toward optimizing the QC criteria is ongoing, however 


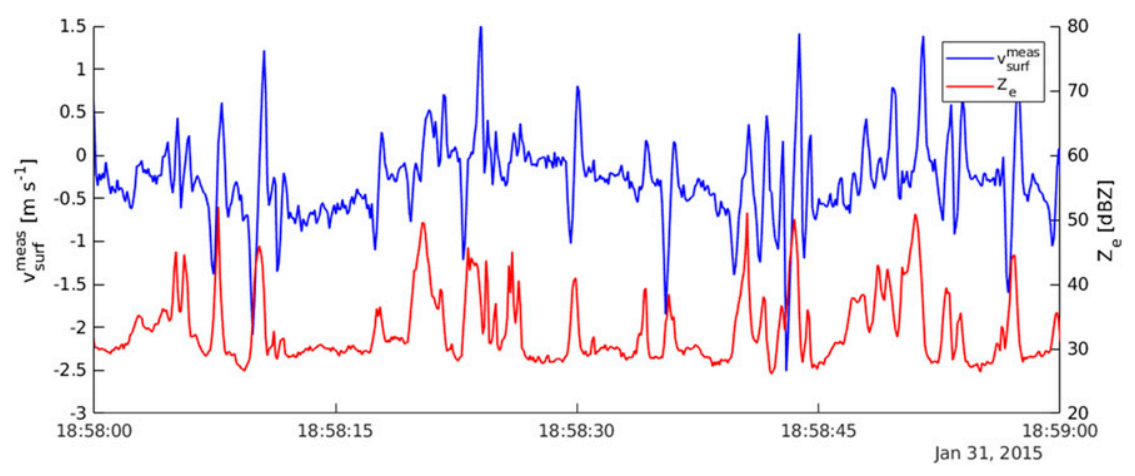

FIG. A1. A 1-min time series of $\mathrm{Ze}_{\text {surf }}^{\text {meas }}$ (red) and $\mathrm{Vr}_{\text {surf }}^{\text {meas }}$ (blue) observed during the ferry flight to the Nor'easter project from 1858 to 1859 UTC 31 Jan 2015. The aircraft was over Kansas.

automated QC criteria can never replace examination by experts.

Acknowledgments. The authors are grateful to all of the participants of Nor'easter, CSET, and SOCRATES for their dedication and excellence in planning, execution and data quality control. We thank Drs. Wiebke Deierling, Wen-Chau Lee, and William Brown for their thorough and helpful feedback. The authors also greatly appreciate the excellent reviews of the three anonymous reviewers. The National Center for Atmospheric Research is sponsored by the National Science Foundation.

\section{APPENDIX}

\section{Examining the Sources of the Surface Anomaly Spikes in Vr and Ze}

The negative and positive deviations in $\mathrm{Vr}_{\text {surf }}^{\text {meas }}$ that are associated with positive deviations of $\mathrm{Ze}_{\text {surf }}^{\text {meas }}$ can be explained by the radar with a finite beamwidth flying over high-reflectivity objects on the ground. The finite beamwidth pointing at nadir means that while the center of the beam is looking straight down there are also sections of the beam that are looking slightly fore and aft. The edges of the beam, in the case of the $0.7^{\circ} 3-\mathrm{dB}$ beamwidth of HCR, point forward and aft by $0.35^{\circ}$ corresponding to a radial velocity magnitude of $1.22 \mathrm{~m} \mathrm{~s}^{-1}$ for an aircraft ground speed of $200 \mathrm{~m} \mathrm{~s}^{-1}$. Radial velocity is a reflectivity weighted measurement, meaning that the targets within the beam with the highest reflectivity will contribute most to the measured Vr. So if the reflectivity is constant across the beam the inbound and outbound components of $\mathrm{Vr}$ measured by the finite-width beam due to platform motion cancel out and the mean is $0 \mathrm{~m} \mathrm{~s}^{-1}$. However, as the radar passes over a local maximum in reflectivity there are gradients of reflectivity within the radar footprint on the ground. As the radar footprint approaches the $\mathrm{Ze}$ maximum, the $\mathrm{Ze}$ is greater in the part of the beam looking slightly forward (inbound $\mathrm{Vr}$ ) than in the part of the beam looking slightly aft (outbound Vr). This results in the overall measured $\mathrm{Vr}$ being negative because the inbound component is weighted more. As the radar footprint moves past the local Ze maximum, the aft-looking part of the beam has higher reflectivity, resulting in the measured $\mathrm{Vr}$ being positive. The overall effect is the negative-positive Vr pairs that are matched in location with positive $\mathrm{Ze}$ spikes as were observed in Fig. 1.

We examined the source of the observed surfaceanomaly spikes in $\mathrm{Vr}_{\text {surf }}^{\text {meas }}$ and $\mathrm{Ze}_{\text {surf }}^{\text {meas }}$. An example of 1 min of $\mathrm{Vr}_{\text {surf }}^{\text {meas }}$ and $\mathrm{Ze}_{\text {surf }}^{\text {meas }}$ data collected over northeastern Kansas on the ferry flight out to Nor'easter from 1858 to 1859 UTC 31 January 2015 is shown in Fig. A1. It can be seen that there are numerous maxima in $\mathrm{Ze}_{\text {surf }}^{\text {meas }}$ (red line) and that most of them are associated with negative/positive pairs of $\mathrm{Vr}_{\text {surf }}^{\text {meas }}$ (blue line) spikes. Some locations that have closely spaced $\mathrm{Ze}_{\text {surf }}^{\text {meas }}$ spikes, the $\mathrm{Vr}_{\text {surf }}^{\text {meas }}$ spikes are less recognizable, which is not surprising.

The location of the Ze spike echoes was found by locating all Ze maxima in Fig. A1 that had peak values greater than $31 \mathrm{~dB} Z$ and were at least $2 \mathrm{~dB}$ above their surroundings. The locations of these peaks were then plotted using Google Earth and the result is shown in Fig. A2. The diamond shapes indicate the location of identified surface-anomaly Ze spikes. There were many different surface features that were associated with the spikes in this $1 \mathrm{~min}$ of data including roads, creeks, and buildings. It is interesting to note that all of the paved main roads in this example were associated with surfaceanomaly spikes, but not all of the creeks. This could be because some of the creeks were dry or obscured at the time. Figure A2b shows a zoom in of the region denoted by the black rectangle in Fig. A2a. It is interesting to note that some very small creeks are associated with 

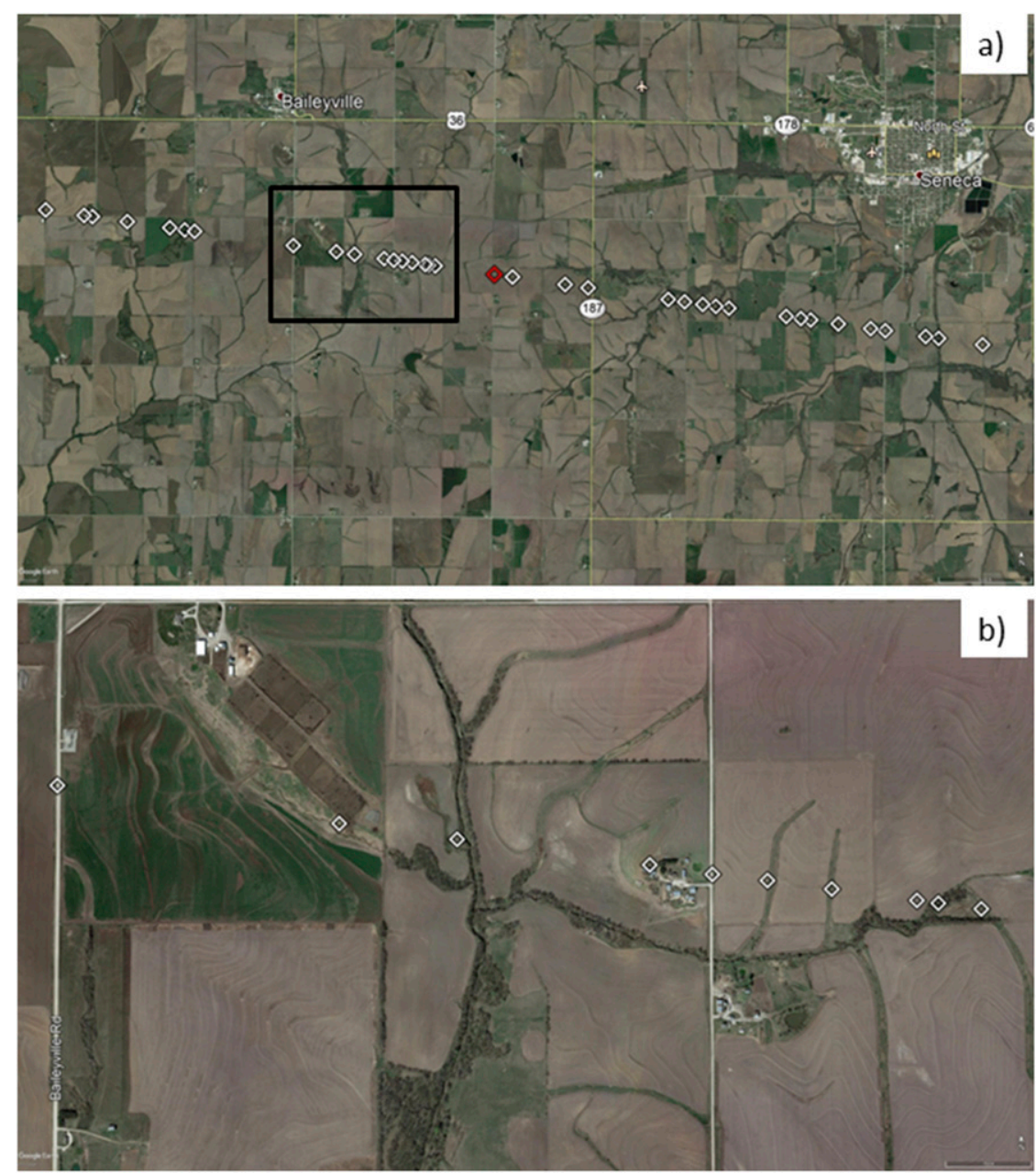

FIG. A2. (a) A Google Earth satellite image corresponding to the data shown in Fig. A1. The diamonds indicate the locations of the $\mathrm{Ze}_{\text {surf }}^{\text {meas }}$ and $\mathrm{Vr}_{\text {surf }}^{\text {meas }}$ anomalies. (b) The region in the black box in (a).

surface-anomaly spikes and others are not. The two larger paved roads in the scene are associated with surface-anomaly spikes, but the small dirt road in between them is not. This does not mean that other dirt roads would not be associated with surface-anomaly spikes.

It is not possible to know what was actually on the surface when the data in Fig. A2 were collected.
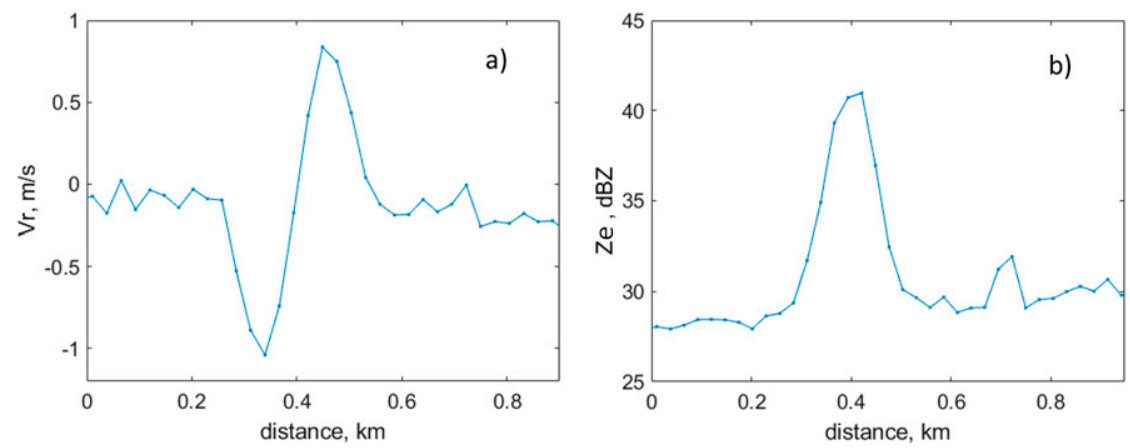

FIG. A3. Plot of (a) $\mathrm{Vr}_{\text {surf }}^{\text {meas }}$ and (b) $\mathrm{Ze}_{\text {surf }}^{\text {meas }}$ for the surface anomaly due to a road shown in the red diamond near the center of Fig. A2a. 


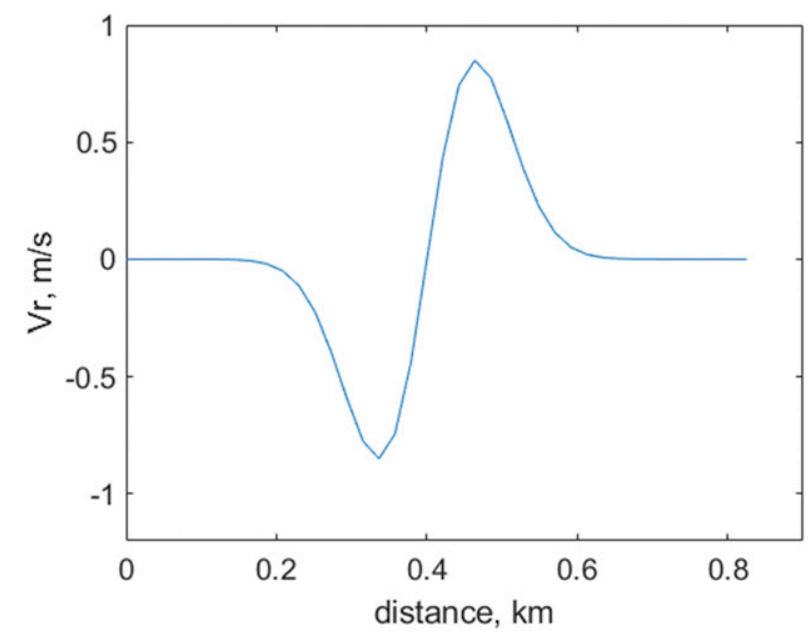

FIG. A4. The result of a theoretical calculation of $\mathrm{Vr}_{\text {surf }}^{\text {meas }}$ for the HCR passing over a 10 -m-wide surface target with reflectivity values about $10 \mathrm{~dB}$ above its surroundings.

However, the rougher surfaces such as fields will scatter more of the radar signal in all directions than the smoother surfaces such as roads, creeks, or possibly the tops of buildings. Thus the smoother roads and creeks will have higher reflectivity values than the fields at near-nadir incidence angles. Interestingly, Cosgriff et al. (1959), as described in Long (2001), measured that the radar cross section (RCS) of a field growing alfalfa was greater than that of an asphalt runway at low incidence angles. However, the RCS of the runway increased with increasing incidence angle while the alfalfa field's RCS remained constant. At about $80^{\circ}$ incident, almost nadir, the runway RCS exceeded the alfalfa field by more than $10 \mathrm{~dB}$. This is consistent with our observations. A thorough description of surface effects on radar signals is available in Long (2001). There were also several $\mathrm{Vr}_{\text {surf }}^{\text {meas }}$ and $\mathrm{Ze}_{\text {surf }}^{\text {meas }}$ spikes observed while the HIAPER was flying over the water near the U.S. Northeast coastline during Nor'easter (not shown). These were perhaps from boats and ships in the water.

The surface-anomaly spike that occurred at 1858:30 UTC and is denoted by the red diamond in Fig. A2a is plotted in Fig. A3. This surface anomaly was associated with a paved road and it is interesting to look into because it is isolated from other spikes that could complicate the signatures. The negative-positive $\mathrm{Vr}_{\text {surf }}^{\text {meas }}$ pair in this case is quite symmetric (Fig. A3a) with a magnitude of about $1 \mathrm{~m} \mathrm{~s}^{-1}$ and the peak $\mathrm{Ze}_{\text {surf }}^{\text {meas }}$ is a little more than $10 \mathrm{~dB}$ above the surrounding values (Fig. A3b). The $x$ axis in the plot is the distance traveled by the HIAPER in the time period of the plot and the individual data points are denoted by the dots. It can be seen that the entire surfaceanomaly signature in $\mathrm{Vr}$ contains about 14 data points.
To add confidence to the explanation of the surfaceanomaly $\mathrm{Vr}$ signatures, a rudimentary calculation was made to simulate the conditions shown in Fig. A3. We modeled the HCR $0.7^{\circ}, 3-\mathrm{dB}$ beamwidth as a Gaussian and moved it along at the average altitude and ground speed of the platform, which were about $12.5 \mathrm{~km}$ and $270 \mathrm{~m} \mathrm{~s}^{-1}$, respectively. A Gaussian peak in surface reflectivity of $10 \mathrm{~dB}$ above the surroundings was computed with a width of about $10 \mathrm{~m}$, in order to represent the road. The simulated $\mathrm{Vr}$ was then calculated and is shown in Fig. A4. The simulated surface-anomaly $\mathrm{Vr}$ negative-positive pair is strikingly similar to that observed in Fig. A3a. The magnitudes of the $\mathrm{Vr}$ anomalies in both simulated and observed cases are about $1 \mathrm{~m} \mathrm{~s}^{-1}$ and the peaks occur in the same location. The overall widths of the features are similar for both observed and simulated cases.

\section{REFERENCES}

Albrecht, and Coauthors, 2018: Cloud System Evolution in the Trades (CSET): Following the evolution of boundary layer cloud systems with the NSF-NCAR GV. Bull. Amer. Meteor. Soc., 100, 93-121, https://doi.org/10.1175/BAMS-D-17-0180.1.

Bosart, B. L., W. C. Lee, and R. M. Wakimoto, 2002: Procedures to improve the accuracy of airborne Doppler radar data. J. Atmos. Oceanic Technol., 19, 322-339, https://doi.org/10.1175/15200426-19.3.322.

Cai, H., W. C. Lee, M. M. Bell, C. A. Wolff, X. Tang, and F. Roux, 2018: A generalized navigation correction method for airborne Doppler radar data. J. Atmos. Oceanic Technol., 35, 1999-2017, https://doi.org/10.1175/JTECH-D-18-0028.1.

Cosgriff, R. L., W. H. Peake, and R. C. Tayler, 1959: Terrain return measurements and applications. Transactions of the 1959 Symposium on Radar Return, University of New Mexico, 11-12.

Doviak, R. J., and D. S. Zrnić, 1993: Doppler Radar and Weather Observations. Academic Press, 562 pp.

Durden, S. L., Z. S. Haddad, and T. P. Bui, 1999: Correction of Doppler radar data for aircraft motion using surface measurements and recursive least squares estimation. J. Atmos. Oceanic Technol., 16, 2026-2029, https://doi.org/10.1175/15200426(1999)016<2026:CODRDF>2.0.CO;2.

Earth Resources Observation and Science Center, 1997: USGS 30 ARC-second Global Elevation Data, GTOPO30. Research Data Archive at the National Center for Atmospheric Research, Computational and Information Systems Laboratory, accessed 31 October 2014, https://doi.org/10.5065/A1Z4-EE71.

Eloranta, E., 2005: High spectral resolution lidar. Lidar: RangeResolved Optical Remote Sensing of the Atmosphere, C. Weitkamp, Ed., Springer, 143-163.

Haimov, S., and A. Rodi, 2013: Fixed-antenna pointing-angle calibration of airborne Doppler cloud radar. J. Atmos. Oceanic Technol., 30, 2320-2335, https://doi.org/10.1175/JTECH-D12-00262.1.

Heymsfield, G. M., 1989: Accuracy of vertical air motions from nadir-viewing Doppler airborne radars. J. Atmos. Oceanic Technol., 6, 1079-1082, https://doi.org/10.1175/1520-0426(1989) 006<1079:AOVAMF $>2.0 . \mathrm{CO} ; 2$. 
— - and Coauthors, 1996: The EDOP radar system on the highaltitude NASA ER-2 aircraft. J. Atmos. Oceanic Technol., 13, 795-809, https://doi.org/10.1175/1520-0426(1996)013<0795: TERSOT $>2.0 . \mathrm{CO} ; 2$.

Hubbert, J., and V. N. Bringi, 1995: An iterative filtering technique for the analysis of copular differential phase and dual-frequency radar measurements. J. Atmos. Oceanic Technol., 12, 643-648, https:// doi.org/10.1175/1520-0426(1995)012<0643:AIFTFT>2.0.CO;2.

Lee, W.-C., P. Dodge, F. D. Marks, and P. H. Hildebrand, 1994: Mapping of airborne Doppler radar data. J. Atmos. Oceanic Technol., 11, 572-578, https://doi.org/10.1175/1520-0426(1994) $011<0572$ :MOADRD $>2.0$.CO;2.

Long, M. W., 2001: Radar Reflectivity of Land and Sea. 3rd ed. Artech House, 560 pp.

Rauber, R. M., S. M. Ellis, J. Vivekanandan, J. Stith, W. C. Lee, G. M. McFarquhar, B. F. Jewett, and A. Janiszeski, 2017: Finescale structure of a snowstorm over the northeastern
United States: A first look at high-resolution HIAPER cloud radar observations. Bull. Amer. Meteor. Soc., 98, 253-269, https://doi.org/10.1175/BAMS-D-15-00180.1.

Schuler, M., 1923: The perturbation of pendulum and gyroscope instruments by acceleration of the vehicle. Phys. Z., 24, 344.

Testud, J., P. H. Hildebrand, and W.-C. Lee, 1995: A procedure to correct airborne Doppler radar data for navigation errors using the echo returned from the Earth's surface. J. Atmos. Oceanic Technol., 12, 800-820, https://doi.org/10.1175/15200426(1995)012<0800:APTCAD>2.0.CO;2.

UCAR/NCAR, 2005: NSF/NCAR GV HIAPER Aircraft. Earth Observing Laboratory, accessed 14 December 2016, https:// doi.org/10.5065/D6DR2SJP.

Vivekanandan, J., and Coauthors, 2015: A wing pod-based millimeter wavelength airborne cloud radar. Geosci. Instrum. Methods Data Syst., 4, 161-176, https://doi.org/10.5194/ gi-4-161-2015. 